\title{
HIGHLIGHT
}

\section{High Resolution Electron Microscopy of Ordered Polymers and Organic Molecular Crystals: Recent Developments and Future Possibilities}

DAVID C. MARTIN, ${ }^{1,2,3}$ JIHUA CHEN, ${ }^{1}{ }^{\text {JUNYAN YANG, }}{ }^{2}$

LAWRENCE F. DRUMMY, ${ }^{4}$ CHRISTIAN KÜBEL $^{5}$

${ }^{1}$ Macromolecular Science and Engineering, 2022 H. H. Dow Building, The University of Michigan, Ann Arbor, MI 48109-2136

${ }^{2}$ Materials Science and Engineering, 2022 H. H. Dow Building, The University of Michigan, Ann Arbor, MI 48109-2136

${ }^{3}$ Biomedical Engineering, 2022 H. H. Dow Building, The University of Michigan, Ann Arbor, MI 48109-2136

${ }^{4}$ Wright Patterson Air Force Base, Materials and Manufacturing Directorate, Dayton, $\mathrm{OH}$

${ }^{5}$ Fraunhofer-Institut für Fertigungstechnik und Angewandte Material forschung, Wiener Straße 12, 28359 Bremen, Germany

Received 15 June 2004; revised 9 November 2004; accepted 14 November 2004 DOI: $10.1002 /$ polb.20419

Published online in Wiley InterScience (www.interscience.wiley.com).

ABSTRACT: High Resolution Electron Microscopy (HREM) has made it possible to directly image the detailed organization of a variety of polymers and organic molecular crystals. For organic materials it is imperative to use low dose techniques that minimize the structural reorganizations that inevitably occur during electron beam irradiation. This article reviews recent developments in low dose HREM from our own laboratory and elsewhere. The developments in closely related microstructural characterization techniques are also reviewed. In the future, the ability to correct the spherical aberration of the objective lens, the use of low voltages to increase contrast, and the use of time-

Correspondence to: D. C. Martin (E-mail: milty@engin. umich.edu)

Journal of Polymer Science: Part B: Polymer Physics, Vol. 43, 1749-1778 (2005) ○2005 Wiley Periodicals, Inc. 
resolved techniques are expected to open new avenues for the ultrastructural investigations of organic materials. New sample preparation techniques, such as the ability to make thin samples by focused ion beam (FIBs), to cut samples with an oscillating diamond knife, and to more conveniently prepare cryogenically solidified specimens, are also expected to be of increasing importance. (C) 2005 Wiley Periodicals, Inc. J Polym Sci Part B: Polym Phys 43: $1749-1778,2005$

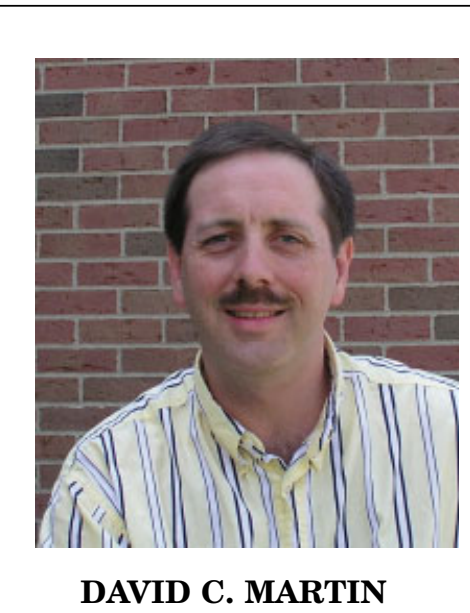

David C. Martin is Professor of Materials Science and Engineering and Biomedical Engineering, and Director of the Macromolecular Science and Engineering Center at the University of Michigan. Prof. Martin is as a Fellow of the American Institute of Medical and Biological Engineering. His research interests include the high resolution imaging of defect structures in polymer and organic molecular crystals, and the development of soft, bioactive polymer coatings for neural prostheses. He received a Ph.D. in Polymer Science and Engineering at the University of Massachusetts with Prof. Edwin L. Thomas, and was a Humboldt Fellow at the Max-Planck Institute for Polymer Research with Prof. Gerhard Wegner. He received an MS in Macromolecular Science and Engineering and a B.S. Eng. in Materials and Metallurgical Engineering from the University of Michigan.

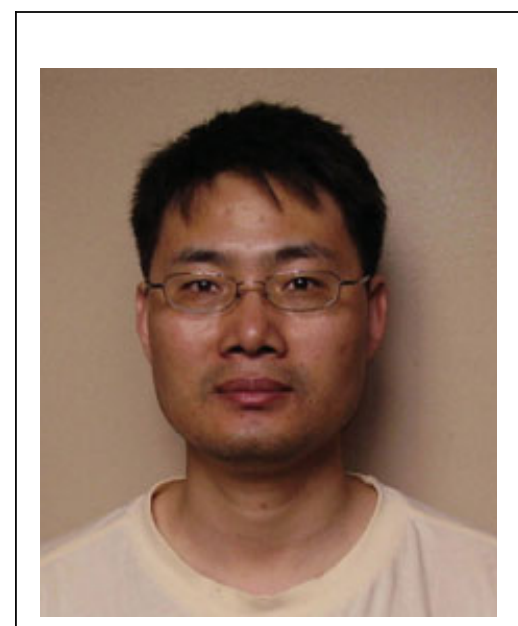

Junyan Yang received his BS and MS degrees from Nankai University, Tianjin, China in 1990 and 1993. He then received his Ph.D. from the Chinese Academy of Science (ACS), Beijing, China. After working at the Institute of Chemistry, he moved to the University of Illinois at Champaign-Urbana in 1998 and the University of Michigan in 2001 as a postdoctoral research fellow. His research interests involve the microstructural and physical characterization of polymers, and nanostructured conducting polymers for neural prosthetic devices, biosensors and actuators. Dr. Yang is currently working for the Dow Chemical Company in Freeport, TX.

\section{JUNYAN YANG}

Christian Kübel is head of the electron microscopy group at the Fraunhofer Institute for Production Technology and Materials Science in Bremen, Germany. His research interests there include 2D and 3D high-resolution structural characterization techniques and their application to adhesion, catalysis and microelectronics. Previously, he held positions as a senior scientist at the Philips Research Laboratory and as a senior TEM application specialist 

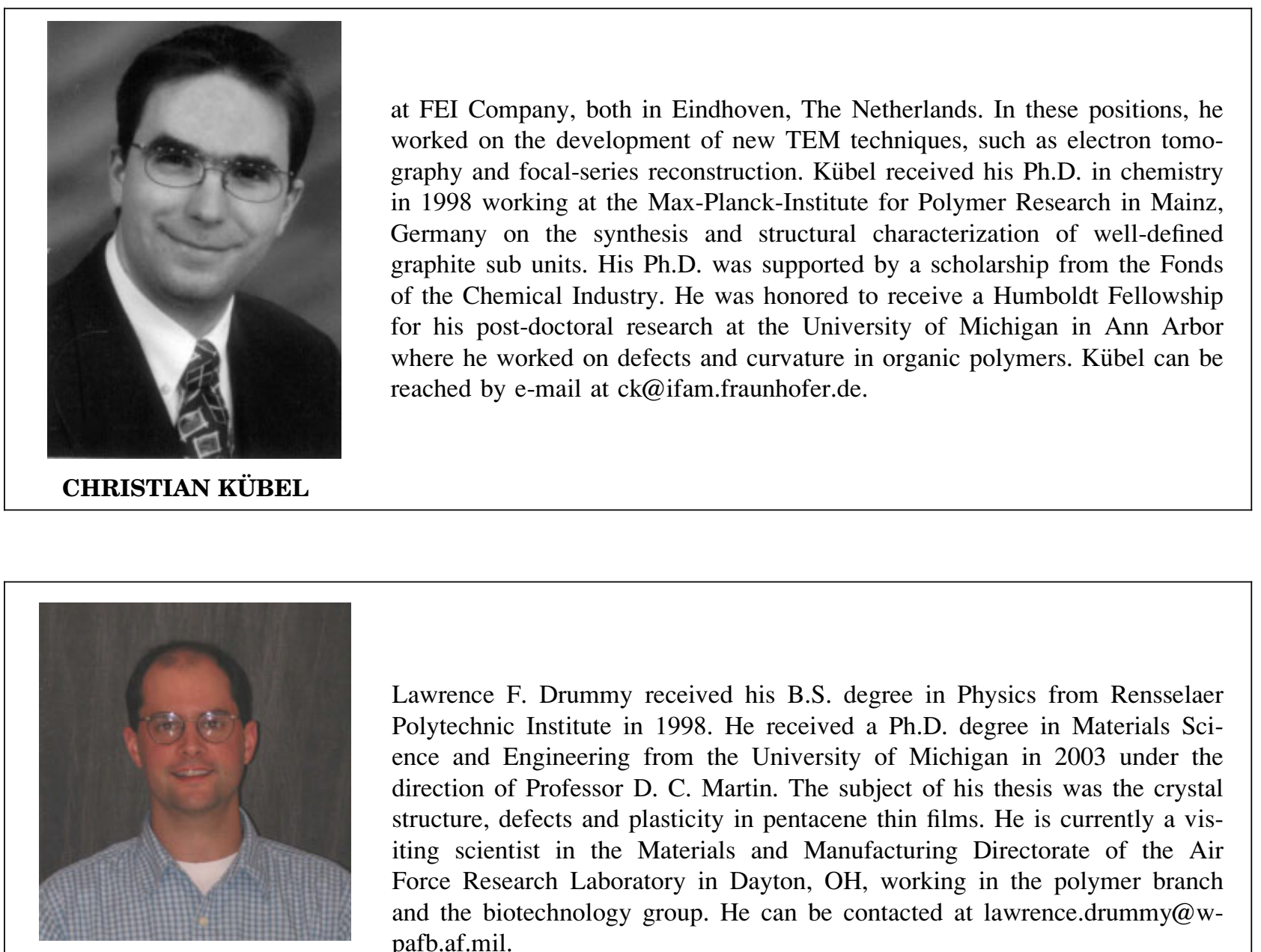

Lawrence F. Drummy received his B.S. degree in Physics from Rensselaer Polytechnic Institute in 1998. He received a Ph.D. degree in Materials Science and Engineering from the University of Michigan in 2003 under the direction of Professor D. C. Martin. The subject of his thesis was the crystal structure, defects and plasticity in pentacene thin films. He is currently a visiting scientist in the Materials and Manufacturing Directorate of the Air Force Research Laboratory in Dayton, $\mathrm{OH}$, working in the polymer branch and the biotechnology group. He can be contacted at lawrence.drummy@wpafb.af.mil.

\section{LAWRENCE F. DRUMMY}

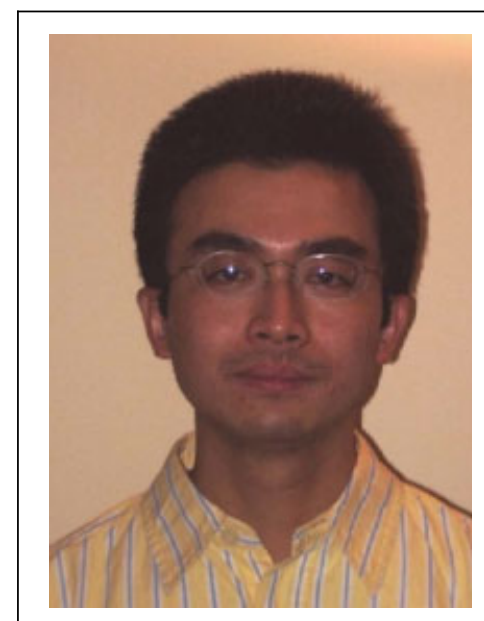

Jihua Chen is a Ph.D. student in Macromolecular Science and Engineering at the University of Michigan in Ann Arbor. In 1997, he graduated from Beijing University of Aeronautics and Astronautics with a Bachelor's degree in Polymeric Materials and Composites. Before coming to Michigan, he studied at Clemson University and obtained his MS in Textiles, Fiber and Polymer Science in 2002. Jihua's research interests focus on structure-process-property relationships of organic molecular crystals. 


\section{INTRODUCTION}

Since 1990 our research group at the University of Michigan has had an active interest in the use of High Resolution Electron Microscopy (HREM) to elucidate the detailed microstructure of a variety of organic molecular and polymer materials. This work has been a continuation of activities that began in 1985 in the Polymer Science Department at the University of Massachusetts at Amherst, under the direction of Prof. Edwin L. Thomas, now at MIT. It also involved a year as a visiting scientist at Dupont Central Research in Wilmington, DE, with Kenn Gardner and Larry Berger (1989-1990), and a year as a Humboldt Fellow at the Max-Planck Institut fur Polymerforschung with Prof. Gerhard Wegner (1997-1998). At the University of Michigan, this work has involved a number of graduate students and postdoctoral scientists, including Patricia Wilson (now at Foster-Miller), Jun Liao (now at Dow Corning), Jaime Ojeda (now at 3M), Marie-Christine Jones (now at General Motors), Chris Buchko (now at Guidant), Lebzylisbeth Gonzalez-Ronda (now at the Ford Scientific Research Labs), Christian Kübel (now at the Fraunhofer Institute in Bremen), and Lawrence Drummy (now at WPAFB). The work is being continued by a current graduate student (Jihua Chen) and a postdoctoral scientist (Junyan Yang). The microscopes at the University of Michigan are mostly located in the North Campus Electron Microbeam Analysis Laboratory (EMAL) under the direction of John Mansfield.

We have previously described the detailed theory and experimental methods of HREM imaging of polymer materials. ${ }^{1}$ Other important and useful reviews on the low dose HREM of organic and polymer materials have been written by Voigt-Martin ${ }^{2}$ and Tsuji and Kohjiya. ${ }^{3} \mathrm{~A}$ more recent but short review of developments in polymer microscopy was presented in 2000 at the EUREM meeting in Brno, Czech Republic. ${ }^{4}$ The purpose of the current document is to discuss the developments that have occurred since 1995 in a broader context, and also to consider how the use of HREM has influenced our fundamental understanding of polymer and organic molecular solids. We specifically elaborate on the use of molecular modeling to elucidate the nature of microstructural defects in polymer and organic molecular crystals, as motivated by
HREM images. Important developments in closely related techniques are also discussed. It seems reasonable to expect that future efforts will continue to improve our level of understanding of these important materials.

\section{INSTRUMENTATION}

The successful HREM imaging of polymers and organic materials makes many demands that are similar to those required for HREM imaging of inorganic materials. These include a short electron wavelength $\lambda$ (high operating voltage), low spherical aberration coefficient $\left(\mathrm{C}_{s}\right)$, and high beam coherence and brightness. Electron guns with tungsten filaments have proven sufficient for relatively low resolution imaging, but the additional coherence and brightness possible with a $\mathrm{LaB}_{6}$ filament is needed for high-resolution microscopy. Most attractive is the high brightness and coherence of a Field Emission Gun (FEG), resulting in a good information limit for ultimate HREM and a high current in a small probe for analytical work. At Michigan our FEG-TEM has been used primarily for analytical microscopy where small probe sizes and high flux are most critical. We have used a $400 \mathrm{kV}$ JEOL 4000EX for most of our HREM efforts. We have recently replaced the nearly 20 year old $400 \mathrm{kV}$ JEOL 4000EX with a $300 \mathrm{kV}$ JEOL 3011. This new microscope has a somewhat lower operating voltage but has several technical advantages, including a side-entry goniometer (perhaps somewhat less mechanically stable but much more rapid sample exchange times, tilting capabilities, and temperature control), more stable electronics, and significantly improved hardware and software control of the microscope operating conditions.

Figure 1 shows a typical low dose HREM image of pentacene, a 5-membered acene that is of particular current interest as the semiconducting active layer in organic thin-film transistors. The predominant $d$-spacings in the image correspond to the $1.4 \mathrm{~nm}$ (001) spacing along the long axis and the $0.45 \mathrm{~nm}$ (110) reflection characteristic of the lateral packing between the pentacene molecules. This typical nanocrystal of pentacene is highly ordered, and the lattice spacings are regular in spacing and orientation throughout the crystal, with no evidence for 


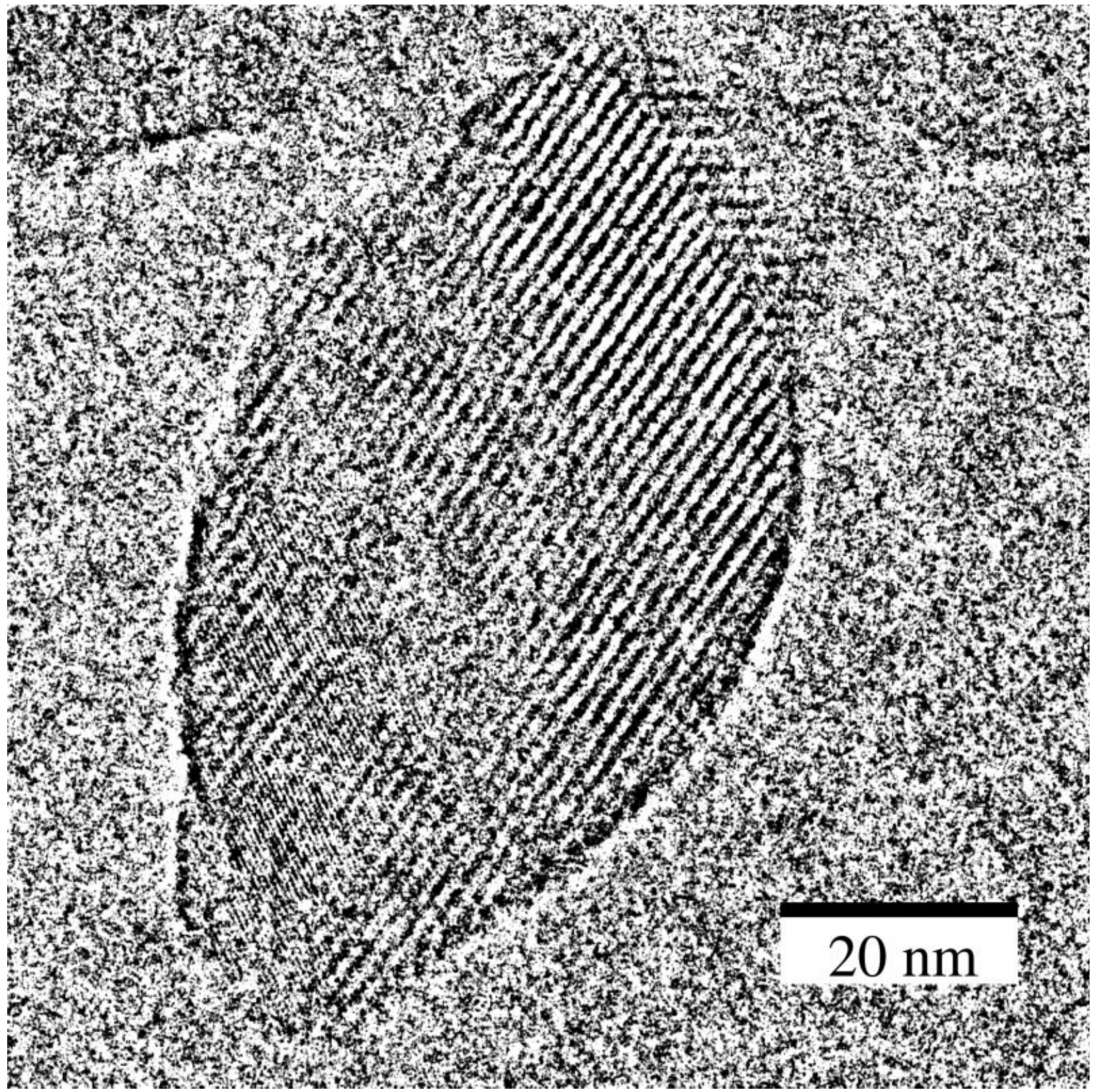

Figure 1. HREM image of a pentacene nanocrystal.

changes in spacing or reorientation near the edges. In more disordered materials, the local change in lattice spacing or orientation can be observed directly from such images.

Table 1 presents a list of the microscopes that have been used in our HREM imaging activities over the years. For instruments with thermionic sources, the smallest dimension that can be reli- ably imaged, $d$, is limited by the spherical aberration $C_{s}$ of the objective lens. The point resolution of a given instrument is estimated by the relationship

$$
d=0.66\left(C_{s} \lambda^{3}\right)^{1 / 4}
$$

which is determined by the first zero in the transfer function of the microscope at Scherzer 

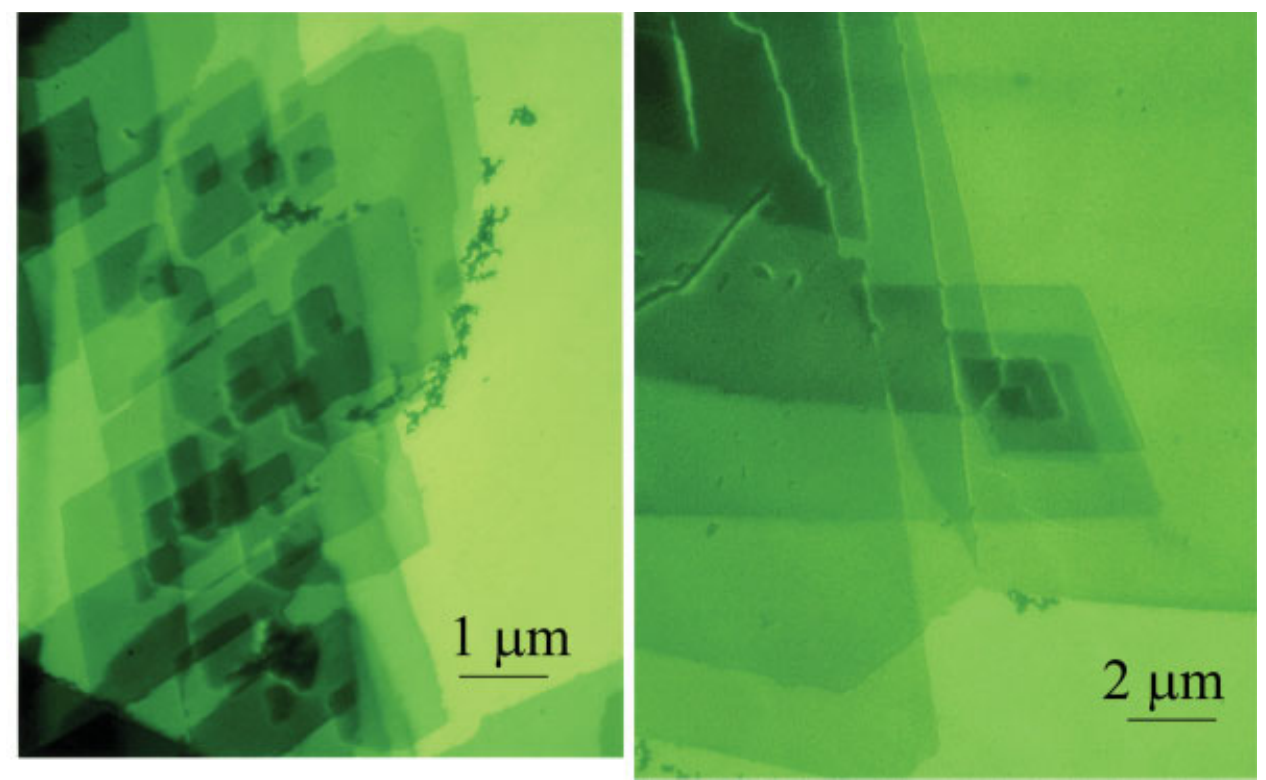

Figure 2. LVEM images of polyethylene lamellar single crystals taken at $\sim 5 \mathrm{kV}$ in bright field TEM mode.

focus. ${ }^{1,5,6}$ Improvements in resolution are possible by increasing the accelerating voltage (decreasing the wavelength) or by decreasing the spherical aberration of the objective lens.

Also shown for comparison in Table 1 are the operating parameters of a low voltage electron microscope (LVEM5) that has recently been commercialized by Delong Instruments in the Czech Republic (http://www.dicomps.com). This unique instrument has a small Schottky field emission

Table 1. Characteristic Operating Parameters of Different TEM Instruments used for Low Dose Imaging of Polymers and Organic Molecular Crystals

\begin{tabular}{lccccc}
\hline & & & & $\mathrm{Cs}$ & \multicolumn{1}{c}{$\mathrm{d}$} \\
Location & Manufacturer & Model & $\mathrm{kV}$ & $(\mathrm{mm})$ & $(\mathrm{nm})$ \\
\hline Umass & JEOL & 2000FX & 200 & 2.3 & 0.29 \\
DuPont & JEOL & 2000EX & 200 & 2.3 & 0.29 \\
Umich & JEOL & $4000 \mathrm{EX}$ & 400 & 0.8 & 0.16 \\
Umich & JEOL & 2010F & 200 & 1 & 0.23 \\
Mainz & Zeiss & 912 & 120 & & \\
Mainz & Philips & CM12 & 120 & 2.0 & 0.35 \\
Umich & Delong & LVEM5 & 5 & 0.6 & 0.88 \\
Umich & JEOL & 3011 & 300 & 0.6 & 0.17 \\
Eindhoven & FEI & Tecnai & 200 & 1.2 & 0.24 \\
& & F20ST & & & \\
\hline
\end{tabular}

source, with permanent magnets for the objective and condensor lens as well as electrostatic intermediate and projector lenses. The instrument operates at high vacuum, with two small ion pumps and a turbomolecular pump that sits on the floor. The images are obtained by focusing a conventional optical microscope on a YAG crystal, and it can operate in TEM, SEM, and STEM modes.

Because of its substantially lower operating voltage, the theoretical resolution of the LVEM5 is not as high as conventional TEM instruments. However, its technical advantages are the extremely small size and significantly increased contrast. The experimental resolution of the LVEM has been estimated as $2.5 \mathrm{~nm} .{ }^{7}$ We have found that the LVEM can provide high contrast images of a wide variety of samples, including dendrimers, microphase separated block copolymers, polymer single crystals, and electrospun nanofibers. ${ }^{7}$

Figure 2 shows an example of an LVEM image of polyethylene single crystals taken in bright field mode. There is high contrast, and the beam can penetrate up to 5 layers of the crystals, corresponding to a nominal thickness of $50 \mathrm{~nm}$. Figure 3 compares an image obtained using a conventional TEM of microtubules (above) with images obtained in the LVEM (below). The images show the uniform diameters 
of the microtubules at high contrast. Figure 4 shows the contrast theoretically expected from imaging the microtubule proteins in the LVEM at $5 \mathrm{kV}$ and the JEOL $4000 \mathrm{EX}$ at $400 \mathrm{kV}$ calculated with Cerius ${ }^{2}$ using the multislice approach for various values of the objective lens defocus in Scherzer units (obtained by dividing the defocus by $\left(\mathrm{C}_{s} \lambda\right)^{1 / 2}$ ). The simulations predict that there should be substantially more contrast at $5 \mathrm{kV}$ than at $400 \mathrm{kV}$.

One of the technical developments that has proven particularly important in refining our HREM technique has been the use of real-time image acquisition and analysis, particularly during the beam alignment stage and final focusing of the image. The ability to rapidly acquire and examine the spatial frequencies of images has been essential for precisely correcting astigmatism and coma in the objective lens system. In practice, this is performed by looking at the real-time digital FFTs of images of a thin amorphous support film (typically carbon). ${ }^{5,6}$

The most important difference between the HREM imaging of inorganic materials and that of organic molecular and polymer materials is the need to be concerned with the significantly increased sensitivity to the electron beam. Once considered to prevent the HREM imaging of these materials altogether, it is now recognized that this is merely an important experimental constraint, and that if properly considered can be dealt with accordingly. However, it is certainly still true that successful operation of the instrument requires an intimate familiarity with the microscope and an appreciation of the image formation process.

To acquire low dose HREM images, we take advantage of beam control electronics and software capabilities that are built into most current microscopes such as the Minimum Dose System (MDS) on JEOL instruments or the Low-Dose Server on Philips/FEI instruments. An essential part of this is a beam-blanking device that allows the beam to be tilted away at a level above the sample while switching modes or inserting a film cartridge, so that the area of interest is only exposed during the actual image acquisition.

We still acquire most of our final data using silver halide based electron imaging film (usually Kodak SO-163 for the JEOL 4000EX and Kodak 4489 for the JEOL 2010F). The limited physical size of currently available CCD detectors ( 1 in. or 2 in. CCD chips) with a relatively large pixel size around 14-30 microns limits the field of view that can be obtained, making it somewhat inconvenient to use the low magnifications that are necessary for low dose HREM. Silver halide film will respond down to a grain size of about 5 microns. We now use a 12-bit, high-resolution Imacon film scanner (5760 dpi $=4.4$ microns) to transfer the film images to digital information, and can quickly conduct complex numerical operations such as FFTs over large regions of the image (4k $\times 4 \mathrm{k}$ pixels or bigger). Note that for the standard $80 \mathrm{~mm} \times 100 \mathrm{~mm}$ film size, this corresponds to a detector size of $13 \mathrm{k} \times 27 \mathrm{k}$ pixels ( $\sim 1 \mathrm{~GB} /$ image). The newest CCD detectors are now $4 \mathrm{k} \times 4 \mathrm{k}$ pixels in size, which is getting close to the information content of film for high-end applications.

For image analysis we often use the public domain software package NIH Image, including the Windows version Scion Image and its newer Java-based version ImageJ. We have written a number of subroutines that have extended the capability of these packages to serve our own specific purposes. More recently we have also found that software packages such as Mathematica provide powerful capabilities for more complex image analysis, and make it possible to be even more general and flexible in our analytical approach. Another popular image processing package is Digital Micrograph, commercially available from Gatan.

For simulating images and diffraction patterns, we have made considerable use of the Cerius ${ }^{2}$ molecular modeling package currently being distributed by Accelrys. One limitation is that the most recent versions only run on SGI UNIX workstations. Some capabilities of $\mathrm{Cerius}^{2}$ are being introduced in the Windows-compatible MS Modeling (formerly Materials Studio), but unfortunately HREM image simulation is not one of the high priority areas. The considerable advantage of Cerius ${ }^{2}$ is that it provides a consistent, single platform for molecule constructing, building of unit cells and defects, and simulations of diffraction patterns and images. Other packages for image simulation are EMS and MacTempas, which are quite powerful for HREM image simulation, but are not as seamlessly integrated into a crystal or molecular building package.

For thin beam-stable samples it has been shown that the full exit-wave function of a specimen can be reconstructed based on a series of HREM images obtained at different objective lens defocus settings. ${ }^{8,9}$ This method has been incorporated into the software package TrueImage commercially available from FEI. The 

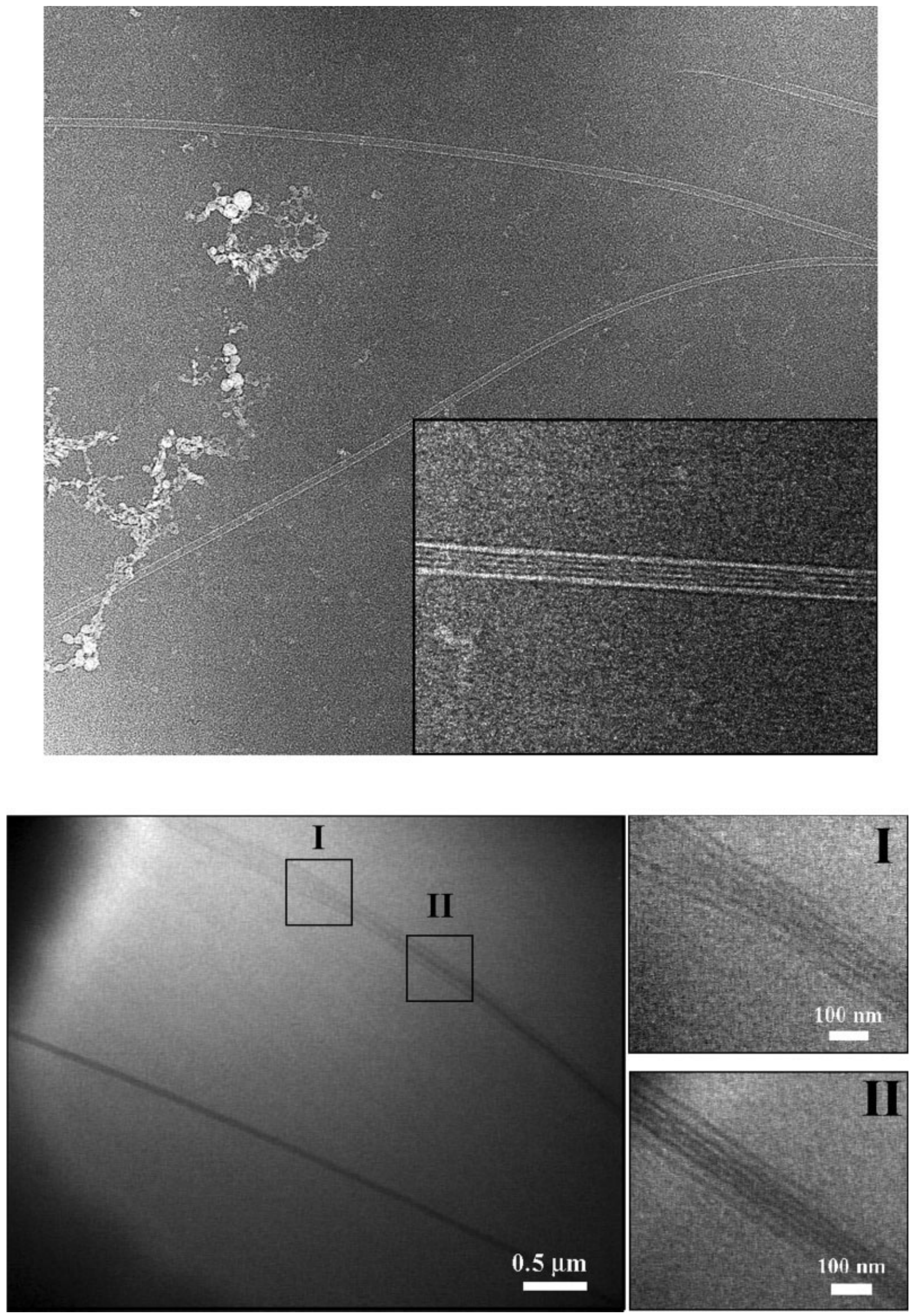


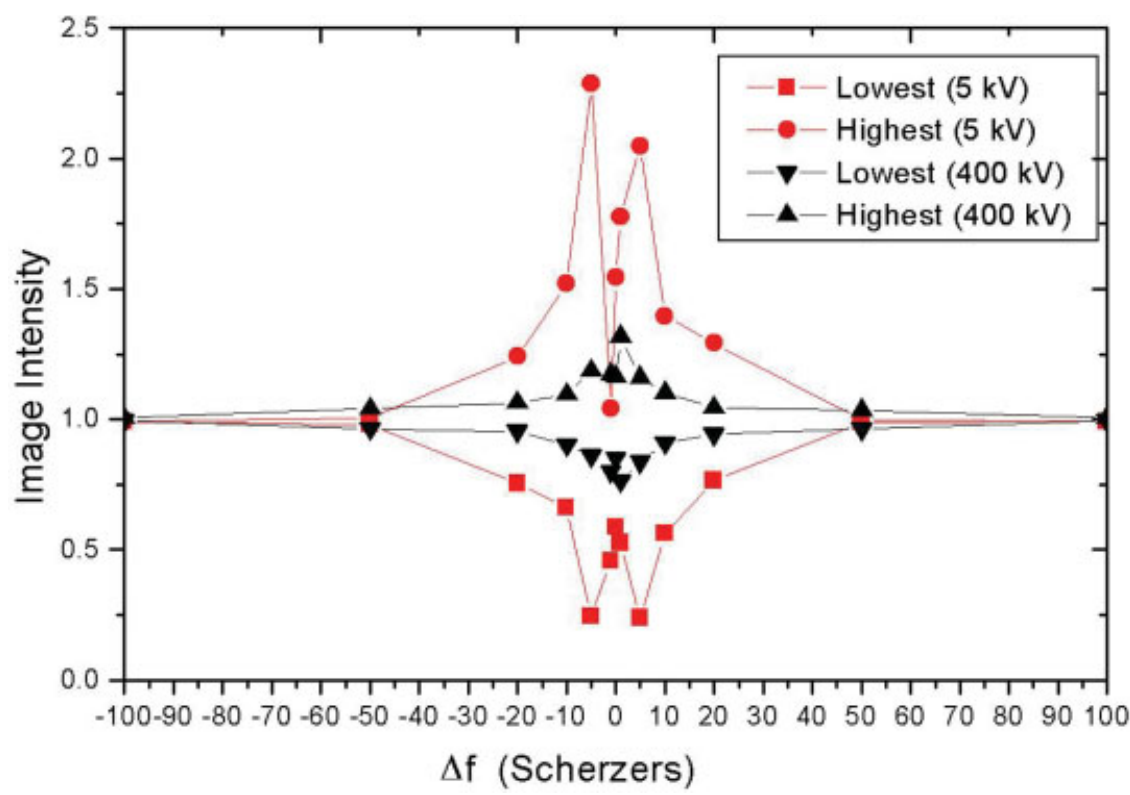

Figure 4. Theoretically calculated maximum (highest) and minimum (lowest) image contrast expected for a crystalline array of microtubule proteins, as estimated by the multslice technique. The images were calculated at $5 \mathrm{kV}$ and $400 \mathrm{kV}$, and plotted as a function of the objective lens defocus in units of Scherzers. The contrast at 5 $\mathrm{kV}$ is predicted to be substantially higher than at $400 \mathrm{kV}$.

information from the exit-wave function can be more directly related to the details of the sample microstructure, such as the relaxations and reorganizations near defects, since the effects due to the spherical aberration of the microscope and contrast delocalization are minimized. Furthermore, it is possible to correct for residual aberrations of the microscope such as astigmatism and coma. However, the fact that several images need to be obtained from the same area will make this approach difficult to pursue on beam-sensitive samples. Normally 10-20 images are required, but 5 might be sufficient for the approach to be feasible.

\section{SAMPLE PREPARATION}

For HREM imaging it is important that the sample be as thin as possible, and be supported on a thin, stable substrate. While holey carbon films have been used for holding samples in HREM, ${ }^{1}$ we have found that uniform thin films of amorphous carbon typically provide the best results for polymers and organic molecular crys- tals, probably because the carbon film underneath helps to stabilize the sample and provides a pathway for charge and heat transport. The films are created by vacuum evaporation onto a freshly cleaved mica sheet, usually about $1 \mathrm{~cm}$ by $4 \mathrm{~cm}$ in size. The mica is split with a razor blade from the side, and is marked to indicate the backside. The mica is ordinarily held on top of a sheet of filter paper in the bottom of a Petri dish. The darkness of the filter paper is used to estimate the thickness of the deposited films. For HREM, only a light gray color is needed to create a film sufficiently thick to provide support for the sample. Quantitative tomographic measurements of a carbon film that caused only a slight difference in gray level on a white filter paper gave an estimate of $5 \mathrm{~nm}$ in thickness.

Samples are usually created by spreading a suspension or solution of the sample over the mica sheet and then allowing the solvent to evaporate. The films are then floated onto the meniscus of distilled water, and lifted onto conventional TEM copper support grids. Alternatively, the carbon films may be floated first and then the samples deposited directly onto the coated grids.

Figure 3. Top: conventional TEM image of microtubules. Image provided by Prof. Edgar Meyhofer, University of Michigan. Bottom: LVEM images of microtubules. 


\section{Electron Beam Sensitivity of Polymers and Organic Molecular Crystals}

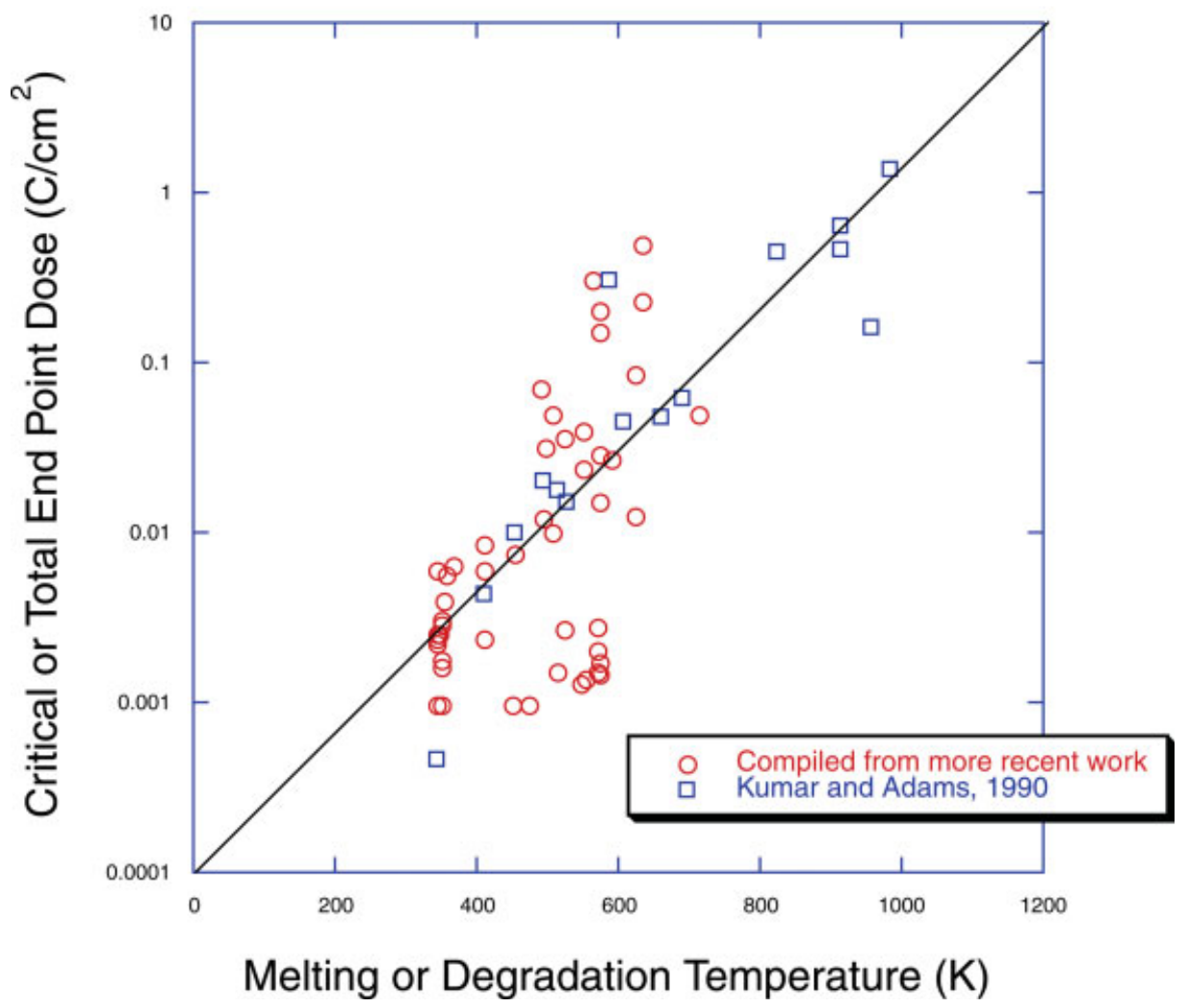

Figure 5. Relationship between thermal stability of polymers and their electron beam stability.

In addition to amorphous carbon, we have also investigated the use of amorphous boron/ boron oxide as a potential support film for TEM imaging. ${ }^{10}$ This route may be particularly interesting if the goal is to use selected energy filtering to examine an organic molecule. ${ }^{11}$ In this case there should be strong contrast between the carbon-rich molecule and the boron support film. However, these films were found to be much less environmentally stable than amorphous carbon, with extensive cracking and changes in film texture observed within two weeks after deposition, presumably due to oxidative degradation. ${ }^{10}$

Microtoming may be possible for HREM imaging, but ultrathin sections are needed and this is experimentally challenging. Thinner sections than usual are also needed for LVEM. It is often necessary to coat microtomed polymer sections with a layer of thin amorphous carbon to improve sample stability under the electron beam. One option for improving thin sectioning might be the lateral oscillation of the knife parallel to the blade edge during cutting. It has been reported that this can significantly reduce the amount of compression damage during sectioning by reducing the angle of attack of the blade, similar to slicing a piece of bread with a knife. $^{12}$

Another possibility is the use of focused ionbeam (FIB) instruments. These devices utilize a positively charged beam of gallium that can be used to cut well-defined sections from arbitrary regions on the sample, even when supported on a rigid inorganic substrate. Those few studies that have been done on polymers have shown extremely encouraging results. ${ }^{13,14}$ At Michigan we have recently installed two FIB instruments at EMAL: an FEI Nova 200 Nanolab and an FEI Quanta 200 3D. We expect that these will have important implications for our future sample preparation endeavors.

Cryo-TEM techniques are also becoming more widespread with the recent development of com- 
mercially available instruments. Cryogenic TEM techniques require the use of a rapid freezing unit that will cool an aqueous sample so quickly that the water vitrifies into a glassy state before the onset of crystallization. A cooled sample stage is also required to avoid recrystallization before imaging. The advantage is that samples from aqueous solutions or suspensions can be examined while solidified in a matrix of vitrified amorphous water while maintaining the native structure in solution. ${ }^{15,16}$ Hence, this approach has been of particular interest for biological samples and surfactants. ${ }^{17,18}$ Recent examples of the use of cryo-TEM include the imaging of polypeptide copolymers of interest for making hydrogel scaffolds. ${ }^{19}$ Cryogenic cooling of the sample stage has also been shown to provide some improvements in damage sensitivity. Liquid nitrogen cooled stages are now routinely used in biology labs, and there are discussions about the potential benefits of going to liquid helium temperatures.

\section{DAMAGE SENSITIVITY}

The structural damage of samples exposed to an electron beam is usually characterized by critical dose $\left(D^{*}\right.$ or $\left.J_{c}\right)$ or total end-point dose (TEPD or $\mathrm{J}_{e}$ ). The critical dose (in units of $\mathrm{C} / \mathrm{cm}^{2}$ or $\mathrm{e} / \mathrm{A}^{2}$ ) is defined as the electron flux through unit sample cross section at which the electron diffraction intensity of a given $d$-spacing reflection falls to $1 / \mathrm{e}(\sim 37 \%)$ of the intensity at zero dose $e^{20,21}$. For an organic material, the value of critical dose varies depending upon which $d$-spacing is chosen. Occasionally, elemental peaks in electron energy loss spectroscopy (EELS) are also used to generate critical dose values for beam-sensitive materials. ${ }^{22}$ Normally these values are significantly larger than the corresponding critical doses obtained from an electron diffraction experiment. These differences correspond to the different electron doses needed to cause the destruction of crystallinity (as measured by diffraction) versus the loss of mass (EELS).

Kumar and Adams correlated the beam sensitivity with the thermal stability of a series of polymers with melt or degradation temperatures ranging from 300 to $1000 \mathrm{~K} .{ }^{21}$ They argued that bond breakage caused by beam damage would likely lead to radical formation and loss of crystalline periodicity. For a thermally stable polymer, more electron energy would be needed to reach
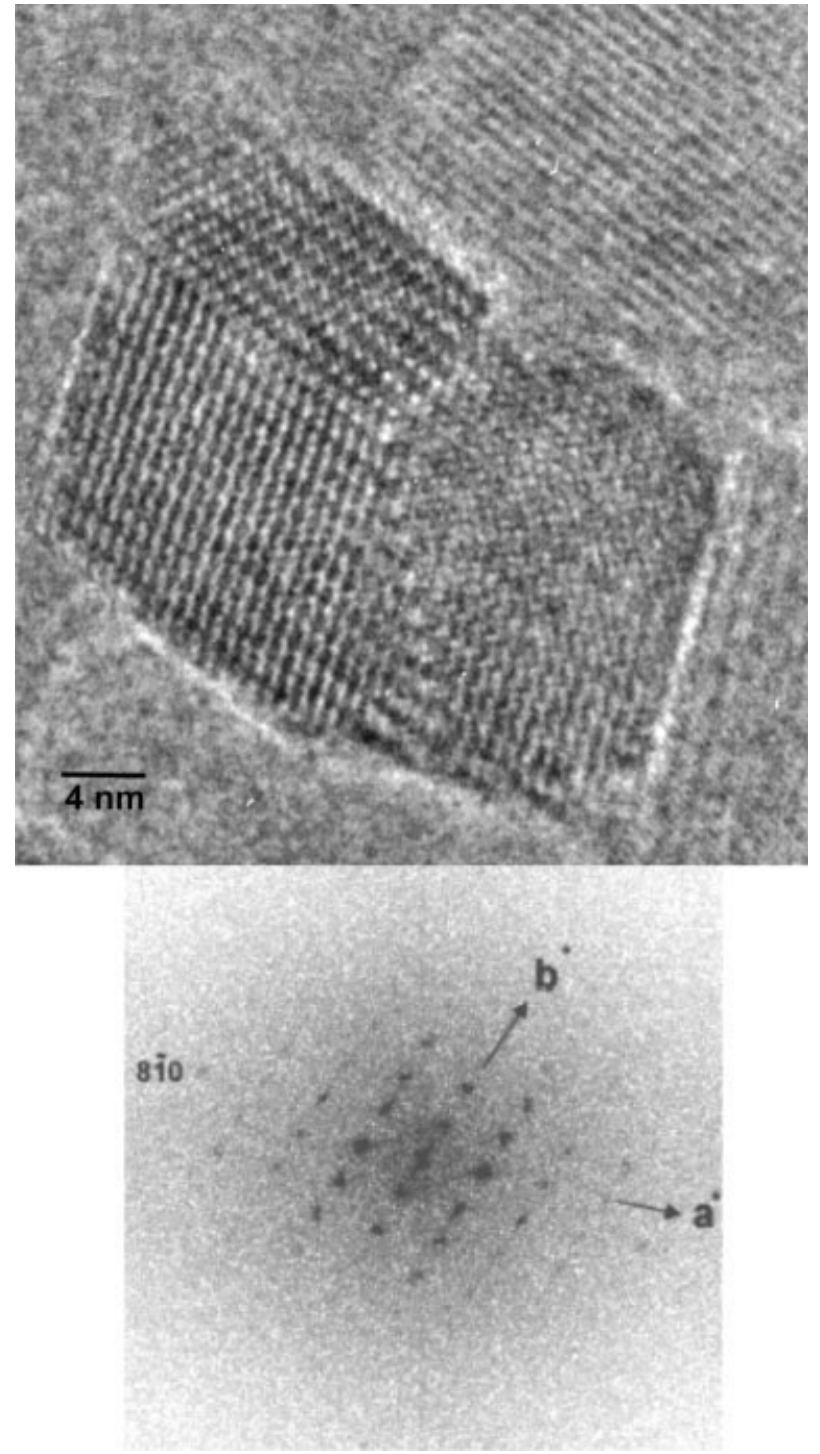

Figure 6. View down the [001] zone of a DCHD nanocrystal showing three individual subgrains. FFT analysis revealed small amounts of misorientation between these domains.

the critical damage point. As they pointed out, many other factors will also affect the electron beam sensitivity, such as morphology, material history, and chemical bonding type, but thermal stability has proven to be a good indicator of the damage sensitivity of polymers and organics to radiation. Here we have included an updated version of the graph showing the correlation between beam stability and thermal stability presented by Kumar and Adams (Fig. 5), showing additional studies from the literature $\mathrm{e}^{23-33}$ and others published more recently. ${ }^{34-40}$

Drummy and colleagues compiled a series of data showing the variation of damage sensitivity 

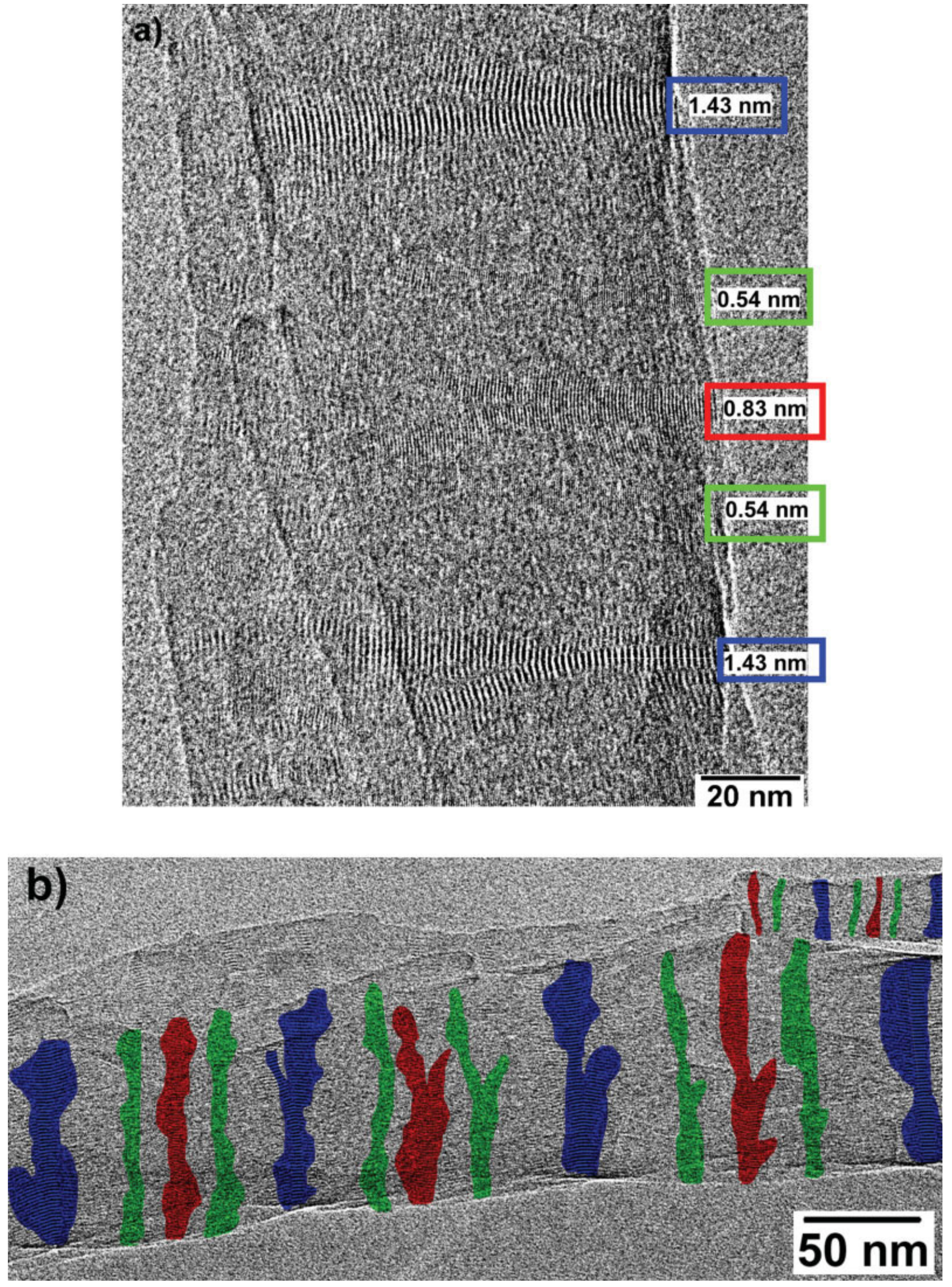
with accelerating voltage in organic materials. ${ }^{7}$ A general trend is observed: below $1 \mathrm{kV}$, the beam resistance decreases as the accelerating voltage goes up; however, above $1 \mathrm{kV}$, the critical dose increases as the voltage further increases. These trends correlate with the total cross section for electron interactions, and therefore this also determines the net image contrast that can be obtained. When the beam interacts with the sample more strongly, the contrast is higher. It was found that this relationship could be reasonably well understood in terms of the expected variation of carbon $\mathrm{K}$-shell ionization events with accelerating voltage. ${ }^{41}$

\section{RECENT RESULTS FROM OUR LAB}

Nanocrystals of poly [1,6-di ( $N$-carbazolyl)-2,4hexadiyne] (polyDCHD) were successfully imaged in three different zones-[100], [120], and occasionally [001]. ${ }^{42}$ Multislice simulations were applied to compare with the experimental HREM images and facilitate data interpretation. Pendellösung plots demonstrated that the intensity variations in experimental HREM images would be significantly affected by even small amounts of disorder (e.g., defects, grain boundaries, and surfaces). Local fast Fourier transform (FFT) comparison was applied to analyze the crystallographic details of a triple-junction grain boundary in the polyDCHD nanocrystals (Fig. 6).

Poly(nonylbithiazole) (PNBT) and poly(nonylbisoxazole) (PNBO) are two electro-optically active materials with similar chemical structure and solid-state packing, but significantly different opto-electronic behavior. The lattice bending of the (100) planes were studied in both polymer samples after annealing, to shed light on their structure-property relationships. ${ }^{43}$ PNBT chains were found to curve in a continuous and coherent manner, while PNBO tended to accommodate their orientation distortion locally. The difference in their deformation mechanism was attributed to variations in sample preparation (including annealing), molecular weight, and the relative stiffness of the polymer chains. ${ }^{44}$

Regularly twisted crystals of poly ( $m$-phenylene isophthalamide) (MPDI) were examined in detail by Kübel and colleagues. ${ }^{45}$ MPDI is a commercially available aromatic polyamide, known as Nomex ${ }^{\circledR}$. When crystallized slowly from dilute solution, it was found that the MPDI formed a new polymorph with a flattened helical conformation that was completely different from the extended chain crystals formed in conventionally spun fibers. These helical MPDI molecules were themselves aggregated into regularly twisted bundles. HREM data exhibited that, along the fiber axis, there was an alternating appearance of four different lattice planes: the

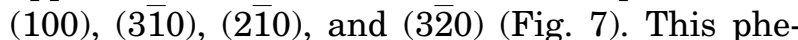
nomenon could be explained by the continuously changed crystallographic projection resulting from the uniform twisting of the polymer chains. There was evidence from direct imaging to support the rationale that the twist-related strain was compensated by lateral shift disorder between the helices (Fig. 8).

The impact of molecular packing on the morphology of oligo ( $m$-phenylene ethynylene) foldamers was studied by examining the endohydrogen and endo-methyl octadecamers. ${ }^{46}$ The former takes a ribbon-like conformation (all trans), whereas the latter packs in a slightly distorted helical way (all cis). Droplets of $0.2 \mathrm{wt} \%$ oligomer solutions were directly imaged by lowdose HREM. In the case of the endo-methyl oligomer, the helices showed bands of (hk0) lattice fringes, and mediated between the bands were disordered areas with no visible fringes. The endo-hydrogen oligomer, on the other hand, had star-like intersections and took bended lamellar shapes. In both foldamers, surface effects were obvious and made the molecular chains bend continuously at the droplet boundary.

Pentacene nanocrystals were studied by Drummy and colleagues. ${ }^{47}$ The nanocrystals were prepared by smashing the commercially available pentacene powder (as-received from Aldrich) between two glass slides. The typical diameters of the resulting crystals ranged from 15 to $150 \mathrm{~nm}$. In most cases, lattice fringes were found to extend to the crystal edges without significant structural reorganization near surfaces (Figs. 1 and 9). Direct imaging of grain boundaries in deformed pentacene nanocrystals demonstrates that penta-

Figure 7. HREM image of a twisted MPDI nanofiber. The periodic appearance of the crystal planes consistent with a hexagonal lateral packing symmetry are imaged along the axis of the needle. The planes are visible as they come in and out of the Bragg condition. In the lower magnification image, the regions showing the different lattice spacings are colored accordingly. (Reprinted with permission from reference 45. (C) 2001 American Chemical Society.) 

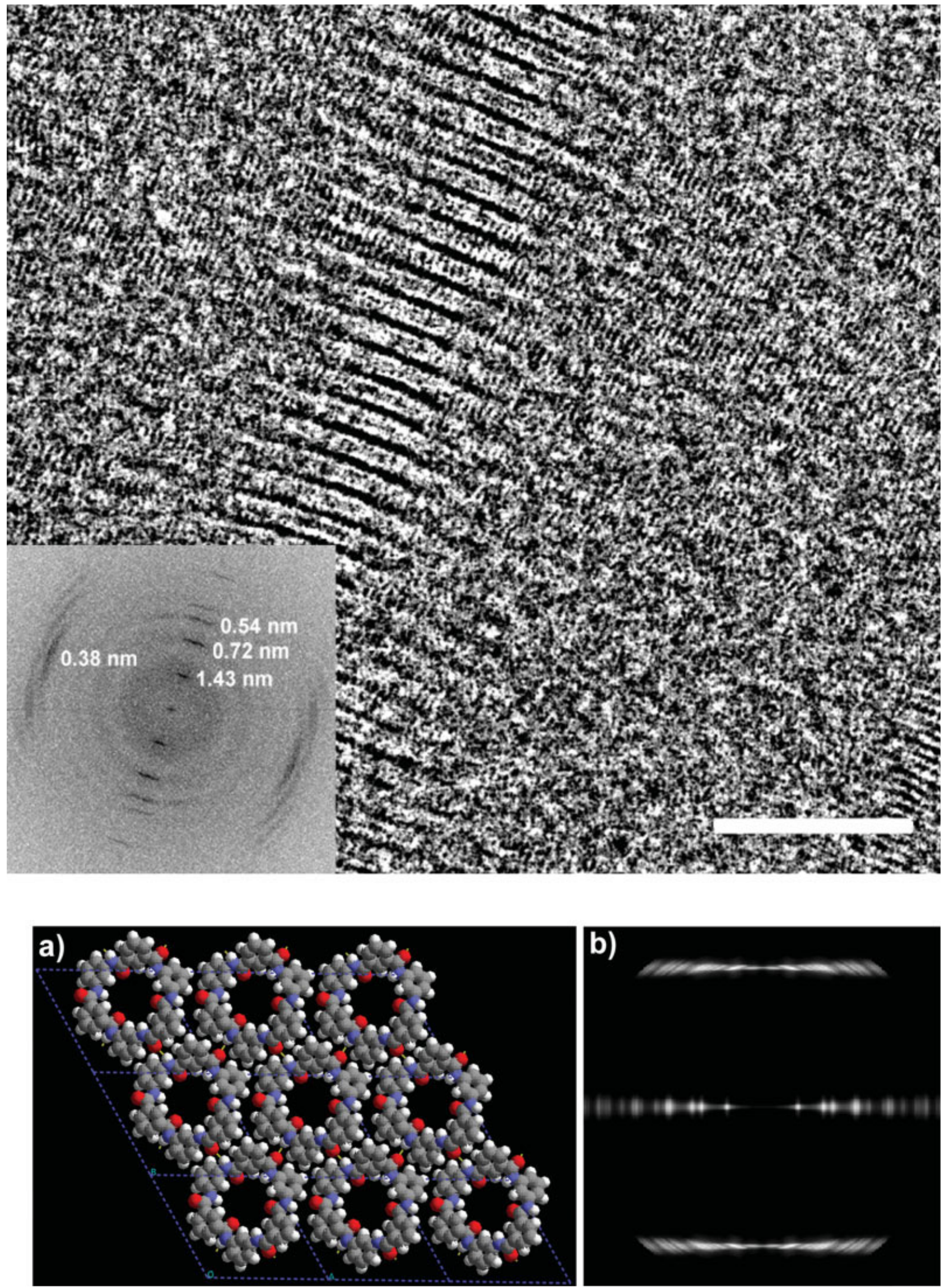


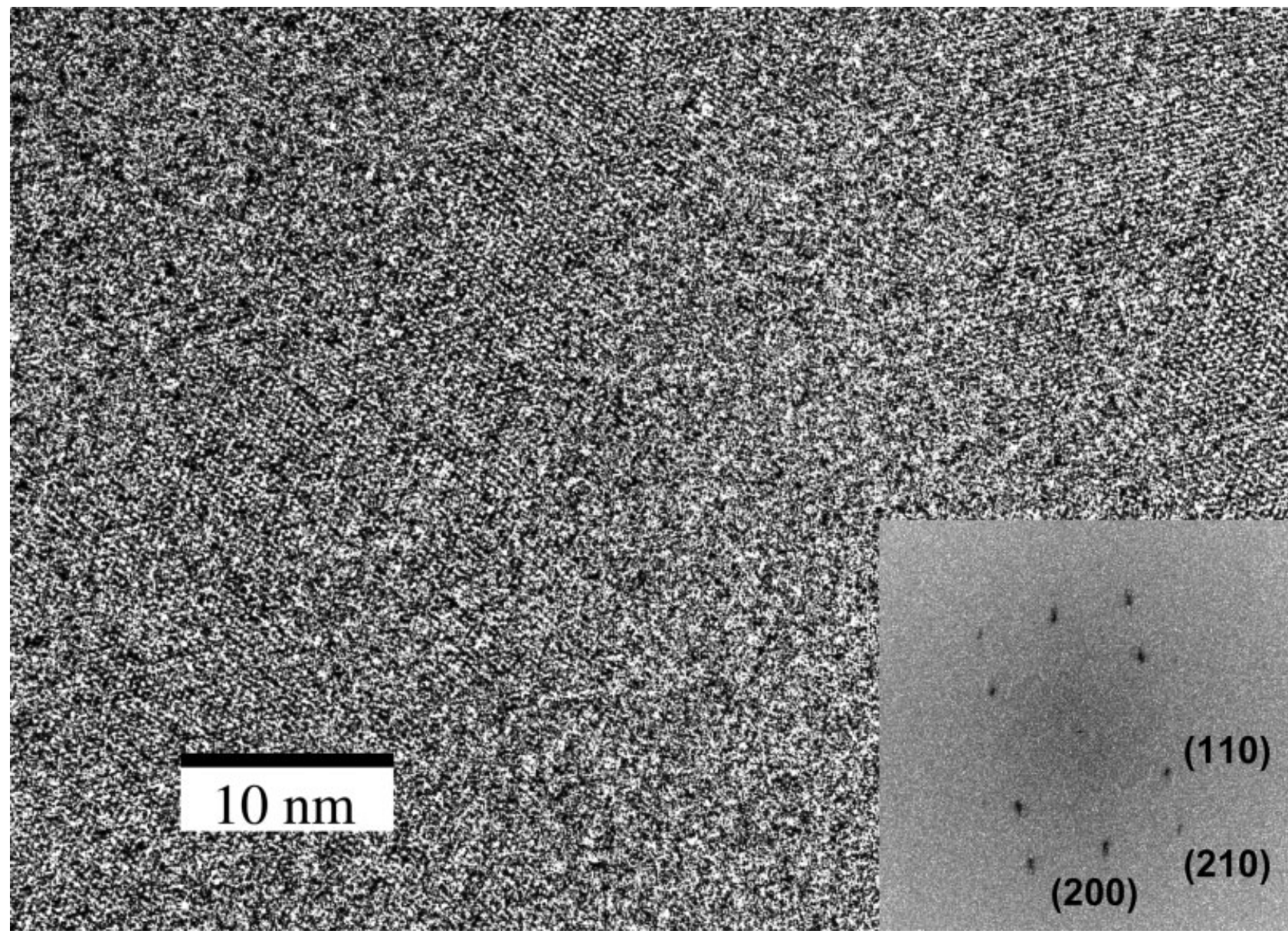

Figure 9. HREM image of a pentacene thin film. The crystal is large and the orientation is essentially perfect and well defined over large distances. The systematic absences in the digital FFT indicate that the thinnest films of pentacene exhibit an orthorhombic symmetry.

cene crystal lattice has the ability to bend continuously across an extended interface. This ability to distribute the local deformation may be advantageous for mediating charge transport across such grain boundaries when these materials are made into thin film transistors.

Figure 9 shows an HREM image of a thin film of pentacene thermally evaporated onto amorphous carbon, showing a high degree of order within an individual large grain. The FFTs of the image show systematic absences at the (100) and (010) positions, indicating that the symmetry of the thin films adopts an orthorhombic symmetry. ${ }^{48}$ This is consistent with electron diffraction patterns from other zone axes from these crystals. Figure 10 shows a pentacene film that was deformed after plastic shear. In this case, the strong $1.4 \mathrm{~nm} \mathrm{(001)}$ fringes can be seen in the image, indicating that the molecules were reoriented from standing nominally perpendicular to the film to lying down parallel to the surface by the deformation field. The local waviness of the crystal planes indicates the extensive disruption of order during this process. Despite the disruption in organization at intermediate length scales, FFTs taken from the center of scratches indicated the development of a preferred contact plane with

Figure 8. High magnification image showing the axial shift disorder between helices necessary to accommodate the strain induced by the twisting of the structure. The scale bar is $10 \mathrm{~nm}$. (Reprinted with permission from reference 45 . (C) 2001 American Chemical Society.) 


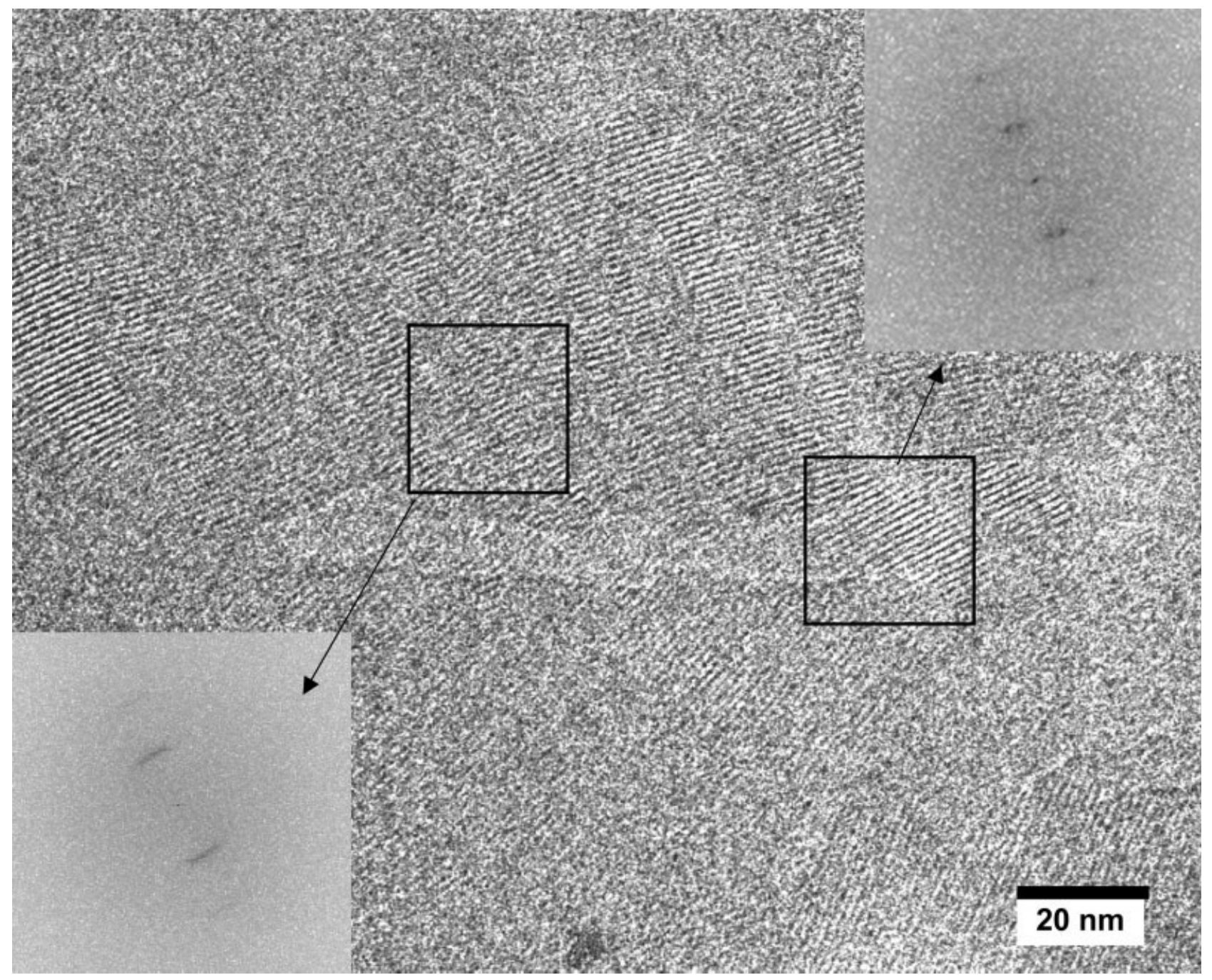

Figure 10. HREM image of a mechanically deformed film of pentacene with the molecular axes now oriented parallel to the plane of the film. The regions of predominant $1.4 \mathrm{~nm}$ (001) spacing are now seen, and evidence for considerable deformation and changes in orientation of these planes is now apparent.

respect to the substrate, consistent with the development of $3 \mathrm{D}$ crystalline order. ${ }^{49}$

Currently there is an HREM study on bis(triisopropylsilylethynyl) pentacene (TIPS-pentacene) underway in our lab. TIPS-pentacene was synthesized by the Anthony group at the University of Kentucky, and was designed to improve the solubility and solid state ordering of the widely studied organic semiconductor pentacene. Unlike the pentacene crystals with the herringbone structure, TIPS-pentacene has a two-dimensional columnar stacking with a relatively close $\pi-\pi$ distance of $0.347 \mathrm{~nm} .{ }^{50}$ Irregularly shaped crystals and nonfacetted edges were common in TIPS-pentacene thin films. Large, highly regular TIPS-pentacene crystals were recrystallized from dilute hexane solution. Lattice fringes of different sizes have been obtained, and those with $0.44 \mathrm{~nm} d$-spacing were consistently seen in several areas of the sample (Fig. 11). Hot stage optical micrographs and electron diffraction experiments have revealed crystallographically regular cracking in the TIPS-pentacene crystals when heated near $130{ }^{\circ} \mathrm{C}$.

HREM images are typically composed of periodically repeating stripes corresponding to the crystalline lattice of the sample. Fourier transform analysis is a common way to study spatial frequencies contained in an image. The individual reciprocal space vectors $\vec{k}$ given by the positions of the reflections in a Fourier transform tell us the 


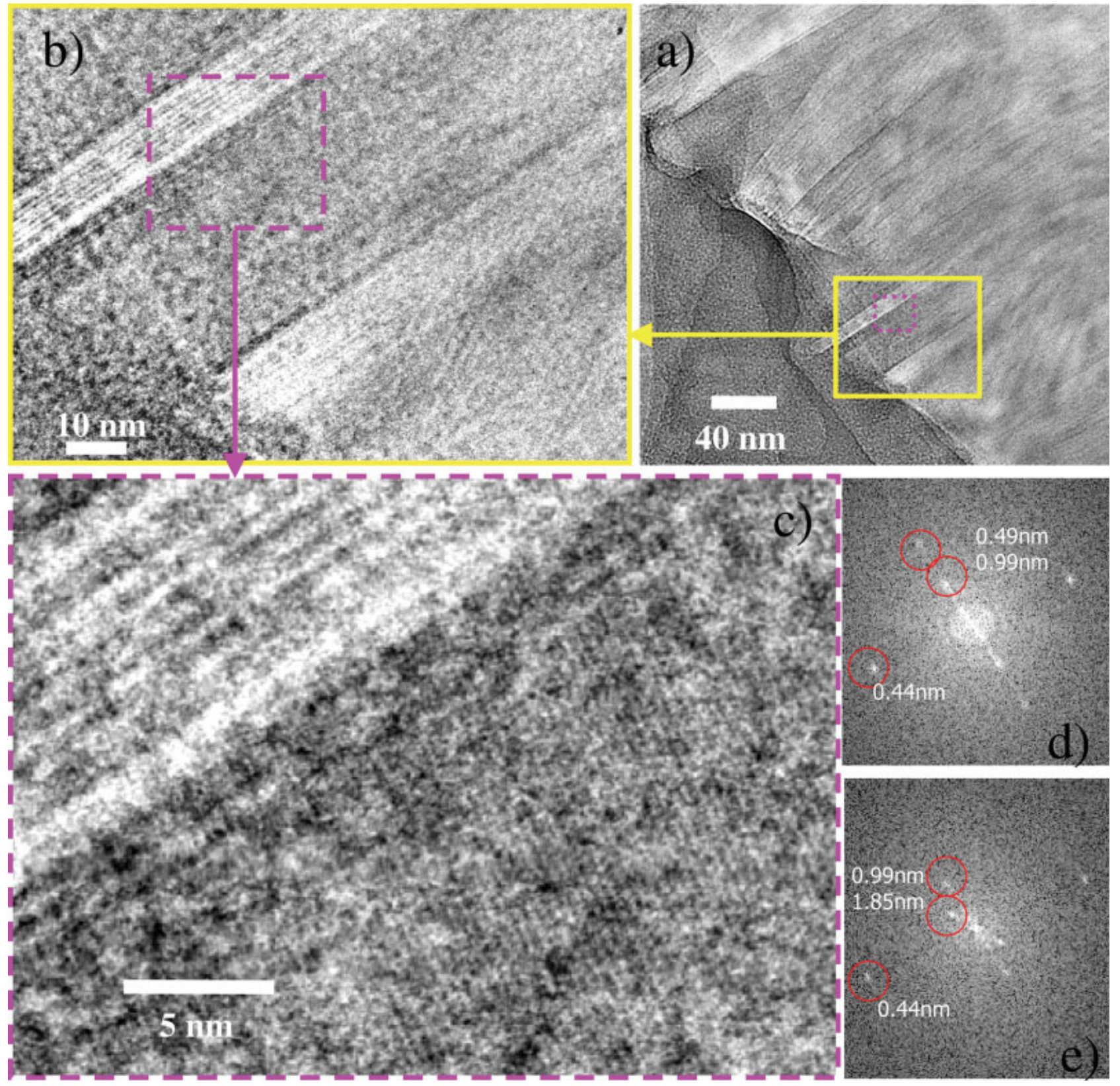

Figure 11. HREM image of a TIPS-pentacene crystal.

magnitude of the vector $|\vec{k}|$ (corresponding to the spatial frequency of the periodicity contained in the image), and the direction of the vector $\theta$ (corresponding to the orientation of the planes in the image). The information contained in the FFT corresponds to the sum of all the spatial frequencies in the image. Changes in the lattice plane spacing or orientation near defects, for example, cannot be directly visualized in the FFT.

Recently, analyses have been developed for extracting information about the variations in the magnitude $|\vec{k}|$ and orientation $\theta$ of images with strong periodic striped domains. This section describes an image analysis algorithm that generates real-space maps of the local changes in $|\vec{k}|$ and $\theta$ measured from an image. This analysis was originally developed to study striped images from Rayleigh-Bénard convection patterns, ${ }^{51}$ block-copolymer microphase separated domain structures, ${ }^{52}$ and smectic liquid crystals. ${ }^{53}$ We have found that the approach is particularly useful for studying defects in periodic HREM images as well. 
For images with periodic intensity variations, the intensity field $u(\vec{x})$ can be approximated as

$$
u(\vec{x})=A(x) \cos [\phi(\vec{x})]
$$

and we are interested in the local wave vector $\vec{k}(\vec{x})$, which is defined as

$$
\vec{k}(\vec{x})=\vec{\nabla} \phi(\vec{x}) .
$$

The components of the wave vector $\vec{k}(\vec{x})$ are well approximated by the second derivatives of $u(\vec{x})$ :

$$
\begin{aligned}
& \left|k_{x}\right|^{2}=-\frac{\partial_{x}^{2} u(\vec{x})}{u(\vec{x})} \\
& \left|k_{y}\right|^{2}=-\frac{\partial_{y}^{2} u(\vec{x})}{u(\vec{x})} .
\end{aligned}
$$

Eqs 3 and 4 give the magnitude of the local wave vector components in the $\mathrm{x}$ and $\mathrm{y}$ directions. To determine the sign of $k_{y}$ relative to $k_{x}$, we use a mixed partial derivative. Choosing $k_{x}$ as positive, $k_{y}$ is then:

$$
k_{y}=-\left|k_{y}\right| \operatorname{sgn}\left(\frac{\partial_{x y} u(\vec{x})}{u(\vec{x})}\right)
$$

where $\operatorname{sgn}(w)=w /|w|$ and $\left|k_{y}\right|$ is determined from $\mathrm{Eq} 5$. The local orientation $\theta$ of the field is determined by:

$$
\theta=\arctan \left[\frac{k_{y}}{k_{x}}\right] .
$$

Figure 12 shows the use of this algorithm to map out variations in the magnitude $|\vec{k}|$ and orientation $\theta$ of lattice fringes in the vicinity of a defect. Figure 12a shows an HREM image of a (hk0) type grain boundary in a textured pentacene film. The digital FFT taken from the image

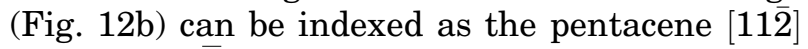
zone. The (110) reflection is split, showing the presence of the grain boundary (or orientational change of the (110) lattice fringes) in reciprocal space. Figure 12c shows the Fourier Filtered image of Figure 12a, overlaid with the real image, generated by selecting only the peaks in the FFT and performing an inverse FFT on those peaks. Figure 12d shows the Fourier filtered image, filtered on the (110) planes. Distortions of the (110) planes near the grain boundary were examined by generating real space maps of the local orientation $\theta$ and local dilation/compression $|\vec{k}|$ of the lattice fringes. Figure $12 \mathrm{e}$, the real space map of the (110) plane orientation $\theta$ of the filtered image $12 \mathrm{~d}$, shows two grains (the blue region and the green region) corresponding to a $7^{\circ}$ orientational change across the boundary. The image also clearly shows the dislocations bridging the boundary, with intermediate stages of lattice fringe orientation above and below each dislocation (light blue regions). Figure $12 \mathrm{f}$ shows $|\vec{k}|$, the magnitude of the wave vector. A low value of $|\vec{k}|$ corresponds to lattice tension and a high value corresponds to lattice compression. The value of $|\vec{k}|$ is equal to the local changes in intensity in the image, so when fringes are spaced far apart (tension), the local changes in intensity in the image are low. When the fringes are close together (compression), the local changes in intensity are high. From dilation/compression maps of the dislocations near this grain boundary, and from other dislocations in the films, it is evident that the lattice is mainly in tension near the core of the defects.

\section{RESULTS FROM OTHER LABORATORIES}

Plummer and Kausch reported the HREM imaging of crystalline order in HBA-HNA thermotropic liquid crystalline polyesters. ${ }^{54}$ They imaged discrete domains of the $0.45 \mathrm{~nm}$ (110) equatorial and the $0.67 \mathrm{~nm}(002)$ meridional reflections. They interpreted these results in terms of the nonperiodic layer (NPL) model proposed by Windle and colleagues, involving the long-range segregation of matching monomer sequences. Evidence for NPL formation has also been argued from dark field imaging. ${ }^{55,56}$ However, given the relatively large size $(10-20 \mathrm{~nm})$ of and uniformity in lattice spacing of the observed domains, an alternative explanation could be the formation of crystals due to reorganizations in the monomer configuration relative to the chain axis, perhaps enhanced due to transesterification reactions that can occur in these materials in the solid-state at elevated temperatures. ${ }^{57}$ The possibility of crystallization-induced sequential reordering reactions has long been recognized in polyesters. ${ }^{58,59}$ They have also been shown to occur in blends with other polymers, such as polycarbonates. ${ }^{60}$

The imaging of the $0.626 \mathrm{~nm}$ (110) and 0.52 $\mathrm{nm}(040)$ spacings in crystals of $\alpha$-phase polypropylene was reported. ${ }^{61}$ The images showed evidence in the FFT out to the (130) and (060) reflections, corresponding to a resolution of 0.35 $\mathrm{nm}$. Evidence for a dislocation consisting of an 

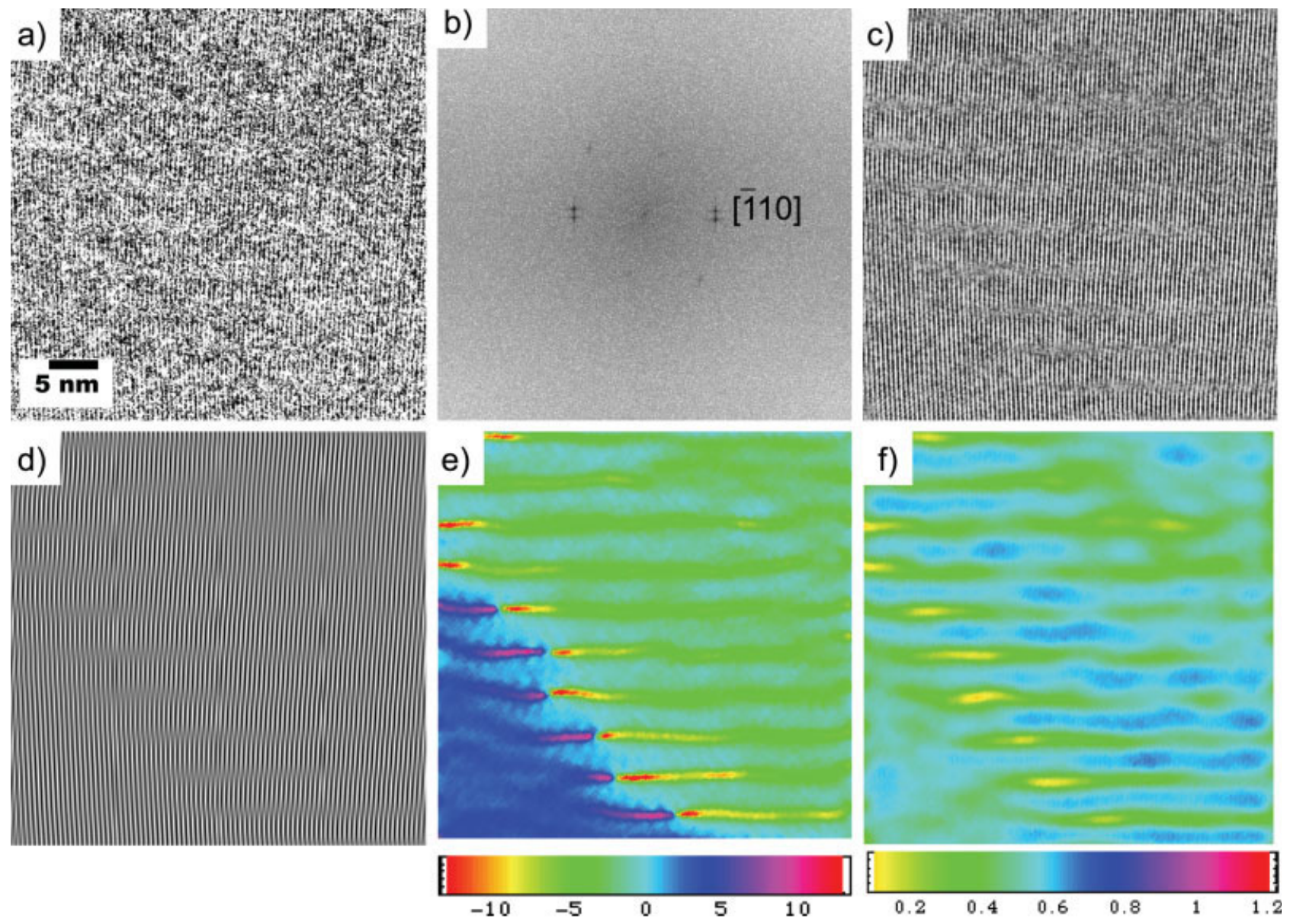

Figure 12. Measurements of the lattice spacing and orientation in an HREM image using the algorithm described in the text.

extra half plane of the (110) planes within an individual polymer crystallite was obtained. The $0.72 \mathrm{~nm}$ (200) fringes in $\beta$-polypropylene were also resolved. HREM images were also recorded on single crystals of poly(ethylene naphthoate) PEN from both the $\alpha$ and $\beta$ polymorphs in several different crystallographic directions, showing lattice spacings out to $0.24 \mathrm{~nm} .{ }^{62}$ The HREM images and digital FFTs of the $\beta$ phase of PEN were shown to be generally consistent with a monoclinic unit cell structure that had been previously proposed. ${ }^{63}$

The direct HREM imaging of cylindrical and spherical supramolecular dendrimers has been achieved. ${ }^{64-67}$ The reported cylindrical dendrimer assemblies had a hexagonal columnar symmetry (P6mm), while the spherical ones formed a cubic structure $(\operatorname{Pm} \overline{3} \mathrm{~m})(\mathrm{a} \sim 4.6 \mathrm{~nm}$ for the cylinders, $\mathrm{a} \sim 8.7 \mathrm{~nm}$ for the spheres).
The direct imaging of individual, extended molecules of phthalocyaninato-poly(siloxane) (PCPS) derivatives was demonstrated in a series of articles. ${ }^{68-70}$ The images showed the uniform diameter and electron density along the macromolecular backbone, and made it possible to discern the trajectory of the individual chains. Information about the packing of the molecules near defects in orientation texture, and the presence of both chain-end and hair-pins on individual polymers was obtained.

Through HREM imaging, Tosaka and colleagues demonstrated that the $\beta^{\prime}$-modification of syndiotactic polystyrene (s-PS) is composed of monoclinic domains. ${ }^{71,72}$ Their data showed that the (110) and (110) fringes (according to their indexing based upon the orthorhombic unit cell reported for the $\beta^{\prime \prime}$ modification) were stacking alternately in the aaxis direction, which fitted well with the proposed 
structural model with two monoclinic domains of distinctive packing motif.

The recent data of Tsuji and coworkers ${ }^{73}$ showed that in isotactic polystyrene (i-PS) thin films, the (300) lattice fringes could be arranged side by side both with and without staggering. The staggered (300) planes gave a smoothly curved lamella, while the registered ones could suddenly change their orientation at a grain boundary. This study provided evidence for two types of proposed space-filling mechanisms: branching and spawning. Since the majority of the lamellae were found to be curved, spawning was suggested to be a more preferred way of crystal growing.

$\mathrm{Bu}$ and colleagues conducted a SAED and HREM study on single-molecule single crystals of i-PS. ${ }^{74}$ Surprisingly, they found that singlemolecule single crystals of i-PS are 50,000 times more radiation-resistant than their multi-molecule counterparts $\left(1000\right.$ versus $\left.0.018 \mathrm{C} / \mathrm{cm}^{2}\right)$. They attributed this dramatic change in beam sensitivity to the small size of the single-molecule crystals, which may facilitate the escape of the secondary electrons and thus reduce the radiation damage efficiently.

Dorset has examined the electron diffraction of a variety of organic molecular compounds, including polydisperse paraffin solutions. ${ }^{75,76}$ His results have shown evidence for the formation of lamellar and "nematocrystalline" phases, depending on the extent of chain end segregation. ${ }^{77}$

Lovinger and colleagues studied thermally evaporated $\alpha, \omega$-dihexyl- $\alpha$-hexathiophene (DH $\alpha 6 \mathrm{~T}$ ) thin films deposited substrates at room temperature $^{78}$ They successfully imaged lattice fringes with a periodicity of $3.6 \mathrm{~nm}$, which corresponded to the $d$-spacing between molecular layers of DH $\alpha 6 \mathrm{~T}$. Their HREM data showed that the thin film was composed of a crystalline percolating network with edge-on alignment and some isolated grains obviously in a different crystallographic orientation. It was suggested that the continuity of the extending fringes across grain boundaries would play an important role in charge transport.

\section{COMPLEMENTARY TECHNIQUES}

For current generation instruments, the main limiting factor that determines the resolution of the microscope is the spherical aberration of the objective lens (Eq 1). Spherical aberration cor- rection had been successfully accomplished on high resolution TEM and STEM by Haider and colleagues $^{79}$ and Batson and coworkers, ${ }^{80}$ respectively. With an objective lens corrector both positive and negative values of $\mathrm{C}_{\mathrm{s}}$ are possible. Lowering the $\mathrm{C}_{\mathrm{s}}$ leads to a significant improvement in resolution and reduction in contrast delocalization. The resolution was improved from $0.24 \mathrm{~nm}$ to better than $0.14 \mathrm{~nm}$ (the information limit of the TEM). An electron probe of subangstrom size was achieved on a $\mathrm{C}_{\mathrm{s}}$-corrected 120kV VG HB501 STEM; more recently, a resolution of $0.075 \mathrm{~nm}$ was reported for an instrument with aberrations measured to fifth order and corrected to fourth order. ${ }^{80}$ Recently, the Oak Ridge group have reported aberration-corrected images of $\mathrm{Si}$ [112] with lattice information resolved down to $0.061 \mathrm{~nm} .^{81}$ These exciting breakthroughs will likely provide new possibilities for defects and crystalline structure study of a variety of materials.

An experimental technique that has proven useful for improving the quality of low dose TEM images is scanning the electron beam intensity in local spots across the sample. ${ }^{82,83}$ This technique has made it possible to image crystals of paraffin with reasonably high contrast. ${ }^{84}$ Another means for potentially improving results is to coat holey carbon support films with metals such as gold or titanium/silicon to better reduce specimen charging. ${ }^{85}$ It was argued that this might prevent the beam-induced movement of the sample that could cause a loss in the expected image contrast. This was supported by FFTs of different regions of the image showing evidence for asymmetry due to specimen movement. The degree of distortion was variable from different regions of the sample, consistent with a mechanism that would depend on the local properties of the material moving during irradiation. Sample drift or astigmatism should be uniform across the field of view. As we discuss in more detail later, one possible means to overcome this problem in the future may be the use of time-resolved or stroboscopic imaging techniques. $^{86}$

The direct imaging of the 3-dimensional structure of materials has become particularly powerful in recent years. ${ }^{87,88}$ By using tomographic reconstruction techniques on a series of 50-150 images acquired over a wide tilt range, it is possible to digitally reconstruct the $3 \mathrm{D}$ structure of a specimen at a resolution in the nanometer range. Spontak has used tomography to image hexago- 


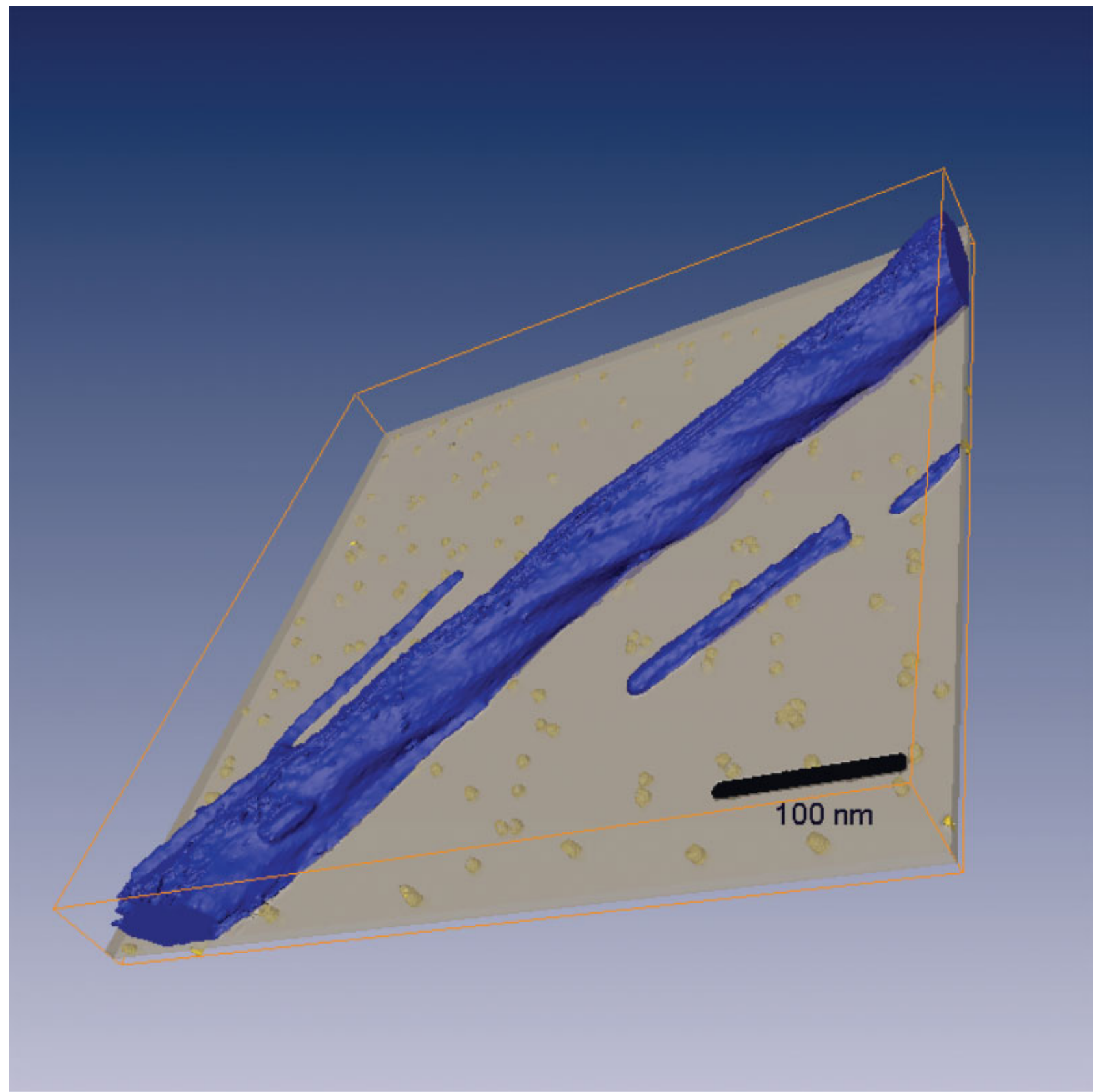

Figure 13. Topographic reconstruction of an MPDI twisted nanofiber. The regular, uniform twisting of the external surface facets on the crystalline bundle is evident.

nal cylinders, bicontinuous phases, and disordered lamellar domains in microphase separated block copolymers. ${ }^{89,90}$ High Angle Annular Dark Field (HAADF)-STEM tomographic techniques can be extended to obtain $3 \mathrm{D}$ reconstructions of a wide range of materials, including composites, catalysts, hydrogen storage materials, and semiconductors. $^{91}$
Figure 13 shows a 3D electron tomographic reconstruction of a helically twisted MPDI crystal, similar to those imaged by HREM (Figs. 7 and 8). The surface shows distinct facets that curve in a continuous fashion, as was expected from the microstructural model of chains twisting around one another. Cross sections along the length of the twisted nanofiber reveal that the 

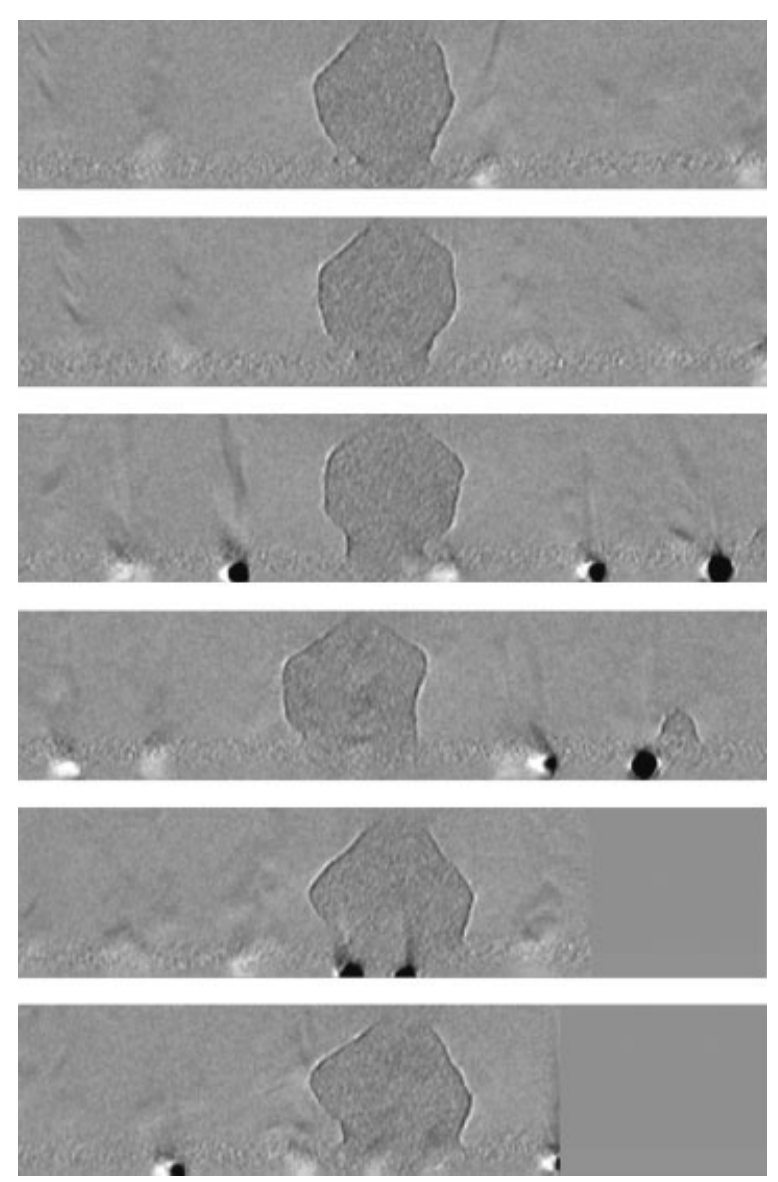

Figure 14. Cross sections of a twisted MPDI nanofiber at several positions along its length. The nominal shape of the cross section is hexagonal, as expected from the lateral crystallographic packing of the MPDI molecular helices.

cross section is nominally hexagonal in shape (Fig. 14), as expected from the lateral packing symmetry between the helical MPDI chains. Recently a similar twisted microstructure has been reported in templated mesoporous silica. ${ }^{92}$

In the future it is possible to envision systems that will help to standardize and automate the sample exchange and analysis of samples in electron microscopes. One effort in this direction is the Leginon system that has been developed for obtaining information from large regions of samples in the TEM. ${ }^{93}$ The focus of the work to date has been on cryo-TEM samples of biological macromolecules. ${ }^{94}$ Robotically controlled, automated sample exchange mechanisms have also been developed. Eventually it may be possible to bring only the samples to the instrument, and allow for the equipment itself to prepare the sample, insert the sample into the microscope, evaluate the sample by automated image analysis and stage translation, and then evaluate the data. This should make it possible for the operator to concentrate on synthesizing the information with other techniques, and to synthesize a wealth of information from different complementary sources.

Using a 2010F FEG STEM, Winey and colleagues studied the impact of certain sample preparation parameters (e.g., recrystallization, $\mathrm{CO}_{2}$ induced plasticization, and neutralization level) on the morphology of different ionomers, such as Zn- or Na-neutralized poly(ethylene-ranmethacrylic acid), Cs- or Zn-neutralized poly (styrene-ran-styrenesulfonic acid), and some Al-crosslinked copolyimide ionomers. ${ }^{95-98}$ For example, the shape, size, and size distribution of ionic aggregates in $\mathrm{Na}$ and $\mathrm{Zn}$-neutralized poly(ethylene-ran-methacrylic acid) (EMAA) ionomers were analyzed. ${ }^{97,98}$ In both cases, the ionic aggregates were found to be close to spherical. STEM tilt series were used in this study to confirm the spherical nature of the aggregates. In the Zn-neutralized EMAA, the aggregate diameters were about $2 \mathrm{~nm}$ and the observed size distribution was nearly monodisperse, independent of the thermal history; whereas in the Na-neutralized EMAA, as-extruded samples were featureless and recrystallized samples generally exhibited macro-phase separation: Phase I with no feature in STEM length scale, Phase II with aggregates of $2-15 \mathrm{~nm}$ diameter, and Phase III with larger spheres of 20-160 nm diameter.

Studies from the Spontak group have shown that even highly plasticized polymer samples can be examined with success in the TEM. Direct images of microphase-separated gel structures in thermoplastic elastomers prepared from poly (styrene-b-(ethylene-co-butylene)-b-styrene) triblock copolymers were obtained with up to $90 \%$ by weight mineral oil. ${ }^{90,99,100}$ These samples were imaged with no apparent complications or evidence of contamination in the electron microscope. This is a dramatic demonstration of the power and flexibility of TEM imaging for the local examination of organic material microstructures.

Fluctuation microscopy is an electron microscopy technique initiated by Treacy and Gibson ${ }^{101}$ to resolve structural information of mediumrange order (nanometer scale) in amorphous materials. The experiments can be performed either using hollow-cone dark field imaging in a conventional TEM, or with a scanning TEM 
(under microdiffraction or imaging mode). ${ }^{102-104}$ By examining the variation in dark field image intensity as a function of a fixed angle of illumination in a hollow-cone geometry, it is possible to extract information about higher order correlation functions in weakly ordered materials. Unlike conventional diffraction, which only probes two-body correlations, information about higher order three-body and four-body correlations have proven to be much more sensitive to subtle variations in microstructure of highly disordered materials. Fluctuation microscopy has been successfully applied to a variety of inorganic disordered materials, such as diamondlike amorphous carbon, amorphous silicon, and germanium. ${ }^{102,105}$ One of the interesting results that has already been obtained is that certain materials that show structural relaxations during annealing are actually evolving toward a more disordered state, which is presumably more stable because of the small crystallite size. The application of this technique to amorphous organics and polymers is yet to be realized; however, it will likely provide important insights about the medium-range ordering of these covalently bonded molecular glasses. Of particular interest would be the ability to distinguish between intramolecular and intermolecular correlations due to the local orientation and packing of the molecules. Of course, any such analyses will need to be careful to take proper account of the electron-beam induced structural transformations that will be inevitable in these organic materials.

Commercially available, highly coherent Field Emission Gun (FEG) sources in TEMs are starting to make more quantitative analysis of contrast during bright field imaging possible-for example, electron holography to estimate the mean inner potential of polystyrene. ${ }^{106} \mathrm{By}$ obtaining phase images from nanospherical particles of known size, it was possible to remove the thickness contribution from the phase shift. The value of the mean inner potential for polystyrene determined in this manner was $8.4 \mathrm{eV}$.

The use of electron energy spectrometers has become quite important for doing local elemental mapping and for improving the quality of images and diffraction patterns. In recent years the in-column Omega lens was developed by Zeiss. Also, Gatan has developed a postcolumn imaging filter (the GIF) that provides capabilities for elemental mapping and filtering diffraction patterns and images. The use of energy filtering for imaging polymers has been reviewed by DuChesne. ${ }^{11}$ An in-line Wien filter is being developed for low voltage electron microscopy as well. ${ }^{107-109}$

\section{MOLECULAR MODELING OF DEFECTS BASED ON HREM IMAGING}

When considering the possible molecular arrangements near defects in solids, it is possible to imagine many different possibilities. However, when these defects are directly imaged by HREM, this significantly limits the number of possibilities, and motivates the more detailed study of this organization using molecular modeling techniques. In several instances we have studied the nature of these arrangements by conducting modeling studies that are based on information obtained by HREM images. Here we provide a few examples of these studies.

A possible defect that can occur in oriented polymer fibers are twists involving two or more molecules that wrap around one another. ${ }^{110}$ We investigated the energetics of such defects in poly(paraphenylene benzobisoxazole) (PBO) using a two-chain unit cell in periodic boundary conditions. The energy of the defect was determined by changing the size of the unit cell and examining the results as a function of the reciprocal of the unit cell size, which is proportional to the defect density. ${ }^{110}$

More recently Hostetter studied the structural evolution in PBO during processing. ${ }^{111}$ His simulations revealed a tendency for the chains to aggregate in a face-to-face fashion as they began to aggregate out of the acid solution. He also saw evidence for the formation of lenticular-shaped crystals, providing a possible explanation for the four-point small angle X-ray patterns that have been observed experimentally. ${ }^{111}$ HREM simulations of the molecular models viewed from the side (along a [hk0]-type zone axis) showed locally crystallized regions containing $0.55 \mathrm{~nm}$ and $0.35 \mathrm{~nm}$ fringes, as seen in experiments. ${ }^{112}$

The isotropic displacement field theories of Taylor and Burgers were compared with information about the lattice orientation near the core of individual edge dislocations in a triblock copolymer system polystyrene-block-poly(ethylene-co-butylene)-block-poly(methyl methacrylate) (SEBM). ${ }^{113}$ The theories predicted that the balance between shear modulus $(\mathrm{G})$ and bulk modulus $(\mathrm{K})$ controlled the nature of the distortion near the defect. Materials with high values of $G$ are 


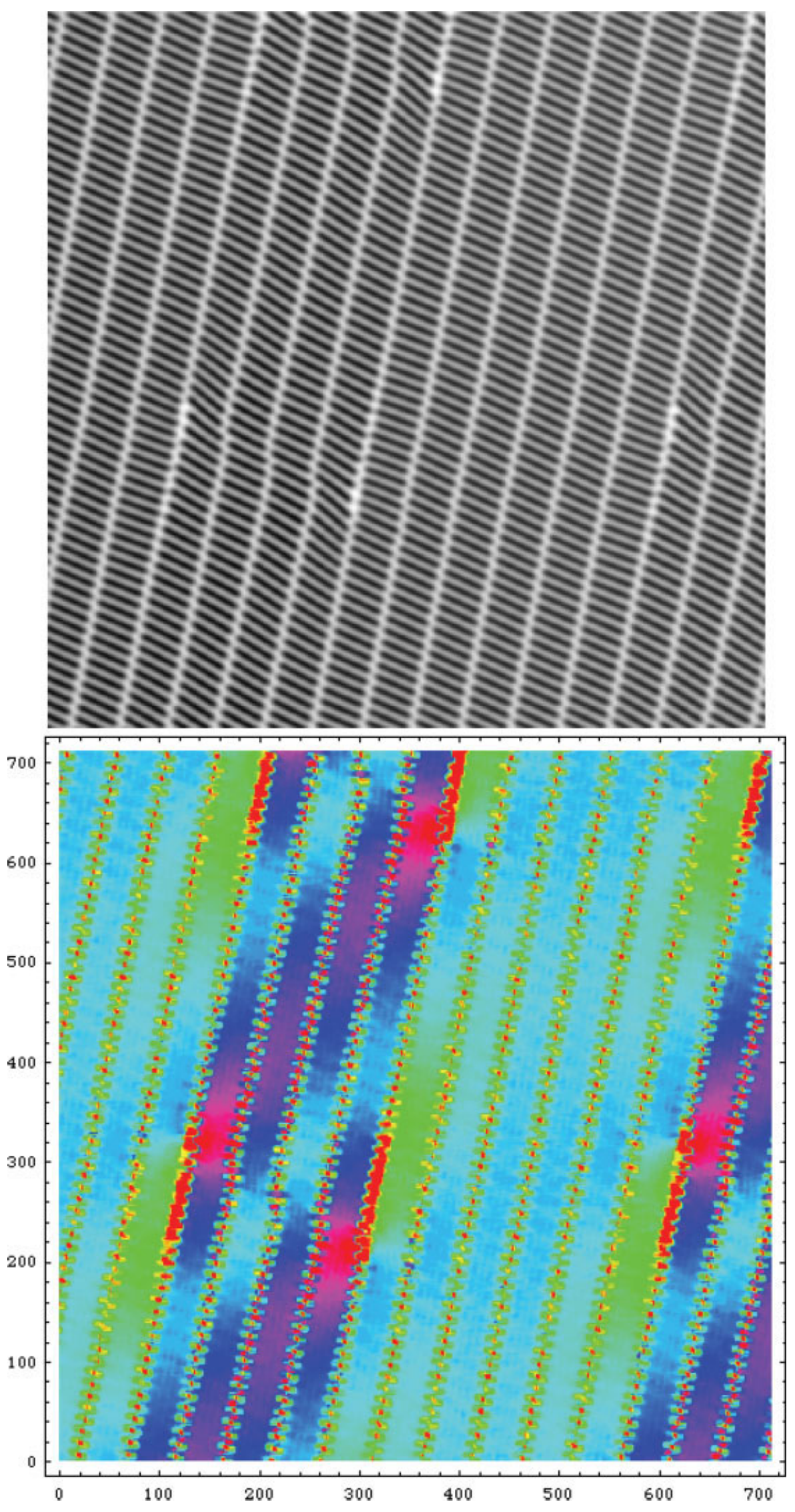


expected to show variations in lattice spacing (dilation and compression), whereas those with relatively high values of $\mathrm{K}$ should show predominantly lattice shear. An estimate of the ratio of $\mathrm{K} /$ $\mathrm{G}=0.8 \pm 0.2$ was obtained for the SEBM copolymer system.

Gonzalez-Ronda studied the conformation of semirigid polymers including PNBT and PNBO by making loops of various sizes. ${ }^{114}$ She found that the chains tended to collapse into flattened rings with a characteristic fold size. The deformation was similar to that seen at the end of a tennis racket, and similar stable shapes have been seen in theoretical studies of intermediate structures that form during collapse of semirigid chains in poor solvents. ${ }^{115}$ This characteristic shape corresponds to the deformation of an elastica, which are thin membranes or fibers that are rigid along their length but have a finite lateral bending elasticity. The deformation of fibers into elastica shapes has been used to estimate compressive strengths. ${ }^{116}$ A similar once-bent shape has recently been used to analyze the adhesion of polymer thin films. ${ }^{117}$

Miska and colleagues calculated the line energy of pentacene edge dislocation dipoles. ${ }^{118}$ The density of dislocations was systematically varied, and it was found that as the density of the dislocations increased, their energy decreased due to strain field overlap. The distortions near the dislocations in the molecular model were analyzed using our algorithm developed earlier, and this provided information about the nature of the anisotropic strain field around the dipole (Fig. 15). We found that the dislocation distributed the strain not between the copy of the dislocation of opposite sign that was the closest, but rather the molecules reorganized in a manner that would not have been predicted for a simple isotropic material. This is presumably related to the anisotropic elastic and plastic character of the pentacene molecular crystals. Low angle grain boundaries in pentacene were also constructed. As the energy of the system was minimized, the dislocations along the grain boundary plane spread out into partials allowing for a more curved interface. The role of defects in mediating the bending and twisting deformations of polymer crystals has recently been reviewed. ${ }^{119}$

Drummy and colleagues have modeled the structure and energetics of molecular vacancies in pentacene. ${ }^{120}$ The experimental electron diffraction pattern of the [001] zone exhibited streaking of two characteristic directions, and this result matched up well with simulated electron diffraction patterns of the pentacene-vacancy models after anisotropic lattice relaxation. According to the simulation, the vacancy formation entropy was calculated to be about 40 times the Boltzman constant $\left(\mathrm{k}_{B}\right)$ at room temperature, and could hardly be negligible when the vacancy concentration of pentacene was being predicted. For atomic vacancies in metals and inorganic semiconductors, the term is around $\mathrm{k}_{B}$ and thus can normally be ignored. This substantive difference in the entropy of a defect may well prove to be a general feature for molecular crystals.

\section{FOCUSED ION BEAM STUDIES OF POLYMERS}

Focused Ion Beam (FIB) instruments use a positively charged beam of gallium ions. These can be focused down to a probe with a nominal diameter of 7-10 $\mathrm{nm}$. The instruments can be used as an SEM, but their real power is in the ability to create well-defined thin sections from arbitrary regions of a sample. The samples can be precisely prepared even on hard substrates.

White and colleagues showed that microphase-separated films of PS-PVP block copolymers deposited on silicon substrates could be sectioned and subsequently examined in the TEM. ${ }^{14}$ The sample thickness was estimated at approximately $20 \mathrm{~nm}$, but this value was not quantified and is not expected to be that accurate. Typical thicknesses of inorganic samples prepared by FIB are more typically in the $50 \mathrm{~nm}$ range. There was a small region of apparent damage near the external surface, but this was correlated with metal deposited during sample preparation, not the FIB itself. Loos and coworkers showed that multilayer films of poly-

Figure 15. Measurements of the lattice spacing and orientation near a molecular simulation of a dislocation dipole in pentacene. The distortions reorganize such that the dislocation does not pick the image of its partner that is the closest, but rather that in a neighboring unit cell. This is apparently to accommodate the anisotropic distortions characteristic of these molecular crystals. 
mer solar cells deposited on indium-tin-oxide (ITO) could be readily prepared by the FIB and imaged in TEM. ${ }^{15}$ The polymer films in this case included PEDOT and doped PPV, as well as Al contact electrodes that were readily sectioned. The film thicknesses and surface roughness were easily imaged, and no apparent damage was observed. The nominal section thickness in this case was estimated at $100 \mathrm{~nm}$, but again this was not determined precisely.

Samples prepared by FIB should provide many opportunities for detailed studies in the future. The ability to keep the sample supported on a hard, inorganic substrate now opens up many situations that were difficult or impossible to pursue with microtoming. If it is true that thin samples can be prepared reliably and reproducibly, this should also be important for LVEM, where the penetration depth of the beam is more limited.

The SEM imaging of organic materials also continues to make progress and improvements. For organic materials is it usually necessary to minimize charging by working near the characteristic crossover point where the number of electrons emitted is equal to the number of primary electrons incident on the sample. This value typically ranges from $0.3-0.8 \mathrm{kV}$ depending on the elemental composition. ${ }^{121}$ Of recent interest is the development of a system to apply a negative bias voltage to the sample. This makes it possible to reduce the amount of charging, significantly improving the resolution possible at low accelerating voltages. ${ }^{122}$ Current generation SEM instruments are capable of resolving features down to about $1 \mathrm{~nm}$ when operating at high voltages. This new beam conditioning system becomes particularly useful at the lower voltages typically used for imaging organics, leading to an estimated improvement of resolution at $1 \mathrm{kV}$ to $1.5 \mathrm{~nm}$ from a value of $3 \mathrm{~nm}$ for a more conventional instrument.

\section{TIME RESOLVED ELECTRON DIFFRACTION AND IMAGING}

Time-resolved transmission electron diffraction was pioneered by Mourou and Williamson. ${ }^{123,124}$ Electron pulses as short as 20 ps were generated with an adapted streak-camera tube. In transmission mode, they demonstrated that laserinduced melting of a 25-nm aluminum film was within $20 \mathrm{ps}$ at an excitation fluence of $13 \mathrm{~mJ} /$
Table 2. Characteristic Times of Various Processes Involved in Electron Beam Damage of Organic Materials (Grubb 1974) $)^{164}$

\begin{tabular}{lc}
\hline \multicolumn{1}{c}{ Event } & $\begin{array}{c}\text { Characteristic } \\
\text { Time (seconds) }\end{array}$ \\
\hline $\begin{array}{l}\text { Energy in electronic excitations } \\
\text { Plasmon decay }\end{array}$ & $10^{-16}$ \\
Vibrational excitations & $10^{-15}$ \\
$\quad$ Radical formation & $10^{-13}$ \\
$\quad$ Dissociation & \\
$\quad$ Internal energy transfer & \\
Electrons captured to & \\
$\quad$ negative ions & $10^{-12}$ \\
Electron energy migration & \\
Spur established & \\
Spur thermal diffusion & $10^{-11}$ \\
Ion and radical & $10^{-10}$ \\
$\quad$ recombination in spur & $10^{-9}$ \\
Luminescence & $10^{-7}$ \\
Ion and radical & $10^{-5}$ \\
$\quad$ recombination in bulk & $10^{-3}$ \\
Molecular motions & $10^{-2}$ and longer \\
\hline
\end{tabular}

Reprinted with permission from reference 164. (C) 1974 Springer Science and Business Media.

$\mathrm{cm}^{2}$. Recently, Siwick and coworkers monitored the same solid-to-liquid phase transformation in an electron diffraction experiment with a 0.5 -ps temporal resolution. ${ }^{125,126}$ They found that the crystallinity loss of 20-nm-thick aluminum samples happened around $3.5 \mathrm{ps}$ at a laser intensity of $70 \mathrm{~mJ} / \mathrm{cm}^{2}$.

Time-resolved Reflective High Energy Electron Diffraction (RHEED) has also been developed to monitor structural changes on various surfaces such as Ge and Pt. ${ }^{127-129}$ Zewail and coworkers adopted a RHEED configuration in their newly developed ultrafast electron crystallography (UEC) instrument to switch their focus from ultrafast gas-phase electron diffraction to condensed phase and surface dynamics. ${ }^{130-134}$ The new UEC instrument has a temporal and spatial resolution of $300-600 \mathrm{fs}$ and $0.001 \mathrm{~nm}$, respectively, and has been successfully applied in dynamics study of interfacial water (ice) on a cold hydrophilic silicon surface.

Considerable work on dynamic studies using time-resolved electron microscopy has been pursued by Bostanjoglo and colleagues. ${ }^{135-159}$ In these studies the beam of a conventional electron microscope was adapted for conducting timeresolved experiments. The ability to monitor the time-evolution of these processes presents consid- 
erable potential for examining dynamic processes such as phase transitions at high resolution.

It should now be possible to take advantage of these picosecond or even femtosecond electron diffraction and imaging systems to study various dynamic processes and phase transitions in organic molecular crystals, ordered polymers, and biological macromolecules such as proteins or DNA. We are particularly looking forward to seeing detailed work elucidating specific radiation damage mechanisms. If the timescale of an electron pulse is shorter than the characteristic time of individual damage processes, it might be possible to significantly reduce the extent of structural reorganization during irradiation. This might make it possible to significantly increase the total dose to induce damage. It might also facilitate the increased use of other techniques that require significant amounts of beam flux, such as electron energy loss spectroscopy (EELS) or convergent beam electron diffraction (CBED).

This technique also has significant implications for the study of electron beam induced phase transitions in organic materials. Lovinger reported a transformation from a ferroelectric to a paraelectric phase in poly(vinylidene fluoride) copolymers at a characteristic dose of 4$9 \times 10^{-4} \mathrm{C} / \mathrm{cm}^{2}$, which was approximately three times smaller than the dose required for the destruction of the crystallinity $\left(14-21 \times 10^{-4} \mathrm{C} /\right.$ $\left.\mathrm{cm}^{2}\right) .{ }^{160}$ Liao and Martin used dynamic electron diffraction techniques to monitor the solid-state phase transformation from monomer to polymer in crystalline diacetylenes. ${ }^{161-163}$ Here, it was found that the electron dose required to polymerize the sample was $10^{-4} \mathrm{C} / \mathrm{cm}^{2}$, five orders of magnitude smaller than the characteristic dose required to induce beam damage.

The ultimate time resolution for the technique is on the order of a few picoseconds, although the quality of the data at these ultrashort times is moderate. Much more reasonable quality diffraction patterns can be obtained with nanosecond length pulses. As Table 2 shows, this still provides opportunities to explore a wide variety of the dynamic processes that have been proposed to occur during irradiation with electrons. ${ }^{164}$

\section{CONCLUDING REMARKS}

The notion that polymers and organic materials do not have interesting microstructures to observe at the molecular length scale is no longer a serious topic of discussion. The study of defects in organic solids requires more detail because the structures are more complex. The microscopy is more delicate because the organic molecular nature of these materials requires that the total dose be precisely characterized and controlled, but with reasonable care a wealth of useful information can be extracted. We have every reason to expect this to continue in the future.

This work has been primarily supported by the National Science Foundation, and the authors are particularly grateful for that assistance. These grants include NSF DMR-9024876, DMR-9257569, DMR9412254, DMR-9707975, and DMR-0084304, and equipment grants DMR-9704175, DMR-9871177, DMR-0320740, and DMR-0315633. Support has also been provided by DuPont, Protein Polymer Technologies, Hoechst-Celanese, Huntsman Chemical Corp., Revlon, the U. S. Army, the Whitaker Foundation, the National Institutes of Health, and NASA.

The senior author (DCM) would like to thank the contributions of several former students at the University of Michigan, including Patricia Wilson (now at Foster-Miller), Jaime Ojeda (now at 3M), Marie-Christine Jones (now at General Motors), Lebzylisbeth Gonzalez-Ronda (now at the Ford Scientific Research Laboratories), and Greg Hostetter (now at Advent Engineering). The authors also acknowledge the contributions of Paul K. Miska, currently a graduate student at the University of Massachusetts at Amherst. We have also benefited from interactions with scientists at Dow Chemical who have assisted with our Polymer Microscopy workshops, including Robert Cieslinski, Greg Meyers, and Duane Kreuger (now at St. Thomas University in Minnesota). Ongoing discussions with Kenncorwin Gardner, Steve Allen, and Robert Matheson at DuPont have also been helpful. Significant thanks are due to the North Campus EMAL laboratory and the persistent efforts of its director, John Mansfield. The support of the Alexander von Humboldt Foundation and interactions with Prof. Gerhard Wegner, Dr. Gunter Lieser, and Dr. Alexander DeChesne at the Max-Planck Institut fur Polymerforschung in Mainz during a sabbatical leave from 1997 to 1998 are gratefully acknowledged. We also acknowledge helpful interactions with Prof. Ingrid Voigt-Martin at the University of Mainz. The microtubule samples and TEM image were provided by Prof. Edgar Meyhofer at the University of Michigan.

\section{REFERENCES AND NOTES}

1. Martin, D. C.; Thomas, E. L. Polymer 1995, 36, 1743-1759. 
2. Voigt-Martin, I. G. Acta Polym 1996, 47, 311-322.

3. Tsuji, M.; Kohjiya, S. Prog Polym Sci 1995, 20, 259-308.

4. Martin, D. C. 2000, Proceedings of EUREM 2000, Brno, Czech Republic.

5. Spence, J. C. H. Experimental High Resolution Electron Microscopy; Oxford University Press: New York, 1988.

6. Buseck, P. R.; Cowley, J. M.; Eyring, L. HighResolution Transmission Electron Microscopy and Associated Techniques; Oxford University Press: New York, 1988;

7. Drummy, L. F.; Yang, J.; Martin, D. C. Ultramicroscopy 2004, 99, 247-256.

8. Thust, A.; Coene, W. M. J.; Beeck, M. O. D.; Dyck, D. V. Ultramicroscopy 1996, 64, 211-230.

9. Thust, A.; Overwijk, M. H. F.; Coene, W. M. J.; Lentzen, M. Ultramicroscopy 1996, 64, 249-261.

10. DuChesne, A.; Martin, D. C. unpublished, 1998.

11. DuChesne, A. Macromol Chem Phys 1999, 200, 1813-1830.

12. Studer, D.; Gnaegi, H. J of Microscopy 2000, 197, 94-100.

13. White, H.; Pu, Y.; Rafailovich, M.; Sokolov, J.; King, A. H.; Giannuzzi, L. A.; Urbanik-Shannon, C.; Kempshall, B. W.; Eisenberg, A.; Schwarz, S. A.; Strzhemechny, Y. M. Polymer 2001, 42, 1613-1619.

14. Loos, J.; Duren, J. K. J. V.; Morrissey, F.; Janssen, R. A. J. Polymer 2002, 43, 7493-7496.

15. Bellare, J. R.; Davis, H. T.; Scriven, L. E.; Talmon, Y. J of Electron Microscopy Technique 1988, 10, 87-111.

16. Talmon, Y.; Burns, J. L.; Chestnut, M. H.; Siegel, D. P. J of Electron Microscopy Technique 1990, 14, 6-12.

17. Unger, V. M. Curr Opin Struct Biol 2001, 11, 548-554.

18. Sabil, H. R. Nat Struct Biol 2000, 7, 711-714.

19. Nowak, A. P.; Breedveld, V.; Pakstis, L.; Pine, D. J.; Pochan, D. J.; Deming, T. J. Nature 2002, 417, 424-428.

20. Reimer, L.; Spruth, J. Ultramicroscopy 1982, 10, 199-210.

21. Kumar, S.; Adams, W. W. Polymer 1990, 31, 15-19.

22. Briber, R. M.; Khoury, F. J Polym Sci Part B: Polym Phys 1988, 26, 621-636.

23. Baumeister, W. Ultramicroscopy 1982, 9, 151-158.

24. Briber, R. M.; Thomas, E. L. Polymer 1986, 27, 66-70.

25. Downing, K. H. Ultramicroscopy 1983, 11, 229-238.

26. Fryer, J. R. Ultramicroscopy 1984, 14, 227-236.

27. Knapek, E. Ultramicroscopy 1982, 10, 71-86.

28. Lovinger, A. J.; Padden Jr., F. J.; Davis; D. D. Polymer 1988, 31, 15-19.

29. Martinez, J. P.; Locatelli, D.; Balladore, J. L.; Rinquier, J. Ultramicroscopy 1982, 8, 437-440.

30. Misra, M.; Egerton, R. F. Ultramicroscopy 1984, 15, 337-344.
31. Ohno, T. Ultramicroscopy 1984, 15, 319-324.

32. Reimer, L. Ultramicroscopy 1984, 14, 291-304.

33. Tsuji, M.; Roy, S. K.; Manley, R. S. J. J Polym Sci Polym Phys Ed 1985, 23, 1127-1137.

34. Barghout, J. Y. J; Thiel, B. L. Int J Biol Macromol 1999, 24, 211-217.

35. Fossey, S. A.; Kaplan, D. Polymer Data Handbook 1999, 970-974.

36. Mansencal, R. Polymer Data Handbook 1999, 39-48.

37. Masamoto, J. Polymer Data Handbook 1999, 714-721.

38. Ohno, T. Ultramicroscopy 1993, 48, 359-363.

39. Ohno, T.; Sengkoku, M.; Arii, T. Micron 2002, 33, 403-506.

40. Taylor, J. E.; Romo-Uribe, A.; Libera, M. Polymer 2002, 43, 1641-1648.

41. Gryzinski, M. Phys Rev 1965, 138, A336.

42. Kübel, C.; Martin, D. C. Philos Mag A 2001, 81, 1651-1673.

43. Gonzalez-Ronda, L. G.; Martin, D. C. Macromolecules 1997, 30, 1524-1526.

44. Gonzalez-Ronda, L.; Martin, D. C. Macromolecules 2004, 37, 2872-2879.

45. Kübel, C.; Lawrence, D. P.; Martin, D. C. Macromolecules 2001, 34, 9053-9058.

46. Kübel, C.; Mio, M. J.; Moore, J. S.; Martin, D. C. J Am Chem Soc 2002, 124, 8605-8610.

47. Drummy, L. F.; Kübel, C.; Lee, D.; White, A.; Martin, D. C. Adv Mater 2002, 14, 54-57.

48. Drummy, L. F.; Martin, D. C. Adv Mater 2005, 17, 903-907.

49. Drummy, L. F.; Miska, P. K.; Martin, D. C. J Mater Sci 2004, 39, 4465-4474.

50. Anthony, J. E.; Brooks, J. S.; Eaton, D. L.; Parkin, S. R. J Am Chem Soc 2001, 123, 9482-9483.

51. Egolf, D. A.; Melnikov, I. V.; Bodenschatz, E. Phys Rev Lett 1998, 80, 3228.

52. Harrison, C.; Adamson, D. H.; Cheng, Z.; Sebastian, J. M.; Sethuraman, S.; Huse, D. A.; Register, R. A.; Chaikin, P. M. Science 2000, 290, 1558-1560.

53. Harrison, C.; Cheng, Z.; Sethuraman, S.; Huse, D. A.; Chaikin, P. M.; Vega, D. A.; Sebastian, J. M.; Register, R. A.; Adamson, D. H. Phys Rev E 2002, 66, 011706.

54. Plummer, C. J. G.; Kausch, H. H. Polymer 1997, 38, 1745-1748.

55. Spontak, R. J.; Windle, A. H. Polymer 1990, 31, 1395-1400.

56. Spontak, R. J.; Windle, A. H. J Mater Sci 1990, 25, 2727-2736.

57. Schneggenburger, L. A.; Osenar, P.; Economy, J. Macromolecules 1997, 30, 3754.

58. Lenz, R. W.; Go, S. J Polym Sci Polym Chem Ed 1974, 12, 1.

59. Lenz, R. W.; Go, S. J Polym Sci Polym Chem Ed 1973, 11, 2927.

60. Bae, W. J.; Jo, W. H.; Park, Y. H. Macromol Research 2002, 10, 145-149. 
61. Plummer, C. J. G.; Gensler, R.; Kausch, H.-H. Colloid Polym Sci 1997, 275, 1068-1077.

62. Plummer, C. J. G. Macromol Rapid Commun 1999, 20, 157-161.

63. Liu, J.; Sidoti, G.; Hommema, J. A.; Geil, P. H.; Kim, J. C.; Cakmak, M. J Macromol Sci Phys 1998, B37, 567.

64. Hudson, S. D. Curr Opin Colloid \& Interface Science 1998, 3, 125-130.

65. Hudson, S. D.; Jung, H. T.; Percec, V.; Cho, W. D.; Johansson, G.; Ungar, G.; Balagurusamy, V. S. K. Science 1997, 278, 449-452.

66. Jung, H.-T.; Kim, S. O.; Hudson, S. D.; Percec, V. Appl Phys Lett 2002, 80, 395-397.

67. Jung, N. T.; Hudson, S. D.; Lenz, R. W. Macromolecules 1998, 31, 637-643.

68. Fakirov, C.; Lieser, G.; Wegner, G. Macromol Chem Phys 1997, 198, 3407-3424.

69. Ries, R.; Lieser, G.; Schwiegk, S.; Wegner, G. Acta Polym 1997, 48, 536-547.

70. Wu, J.; Lieser, G.; Wegner, G. Adv Mater 1996, 8,151

71. Tosaka, M.; Tsuji, M.; Cartier, L.; Lotz, B.; Kohjiya, S.; Ogawa, T.; Isoda, S.; Kobayashi, T. Polymer 1998, 39, 5273-5275.

72. Tosaka, M.; Tsuji, M.; Kohjiya, S.; Cartier, L.; Lotz, B. Macromolecules 1999, 32, 4905-4911.

73. Tsuji, M.; Fujita, M.; Shimizu, T.; Kohjiya, S. Macromolecules 2001, 34, 4827-4833.

74. Bu, H. S.; Cao, J.; Zhang, Z. S.; Zhang, Z.; Festag, R.; Joy, D. C.; Kwon, Y. K.; Wunderlich, B. J Polym Sci Part B: Polym Phys 1998, 36, 105-112.

75. Dorset, D. L. J of Electron Microscopy Technique 1985, 2, 89-128.

76. Dorset, D. L. Acta Crystallogr 1998, A54, 750-757.

77. Dorset, D. L. Struct Chem 2002, 13, 329-337.

78. Lovinger, A. J.; Katz, H. E.; Dodabalapur, A. Chem Mater 1998, 10, 3275.

79. Haider, M.; Uhlemann, S. Nature 1998, 392, 768-769.

80. Batson, P. E.; Dellby, N.; Krivanek, O. Nature 2002, 418, 617-620.

81. Nellist, P. D.; Chisholm, M. F.; Dellby, N.; Krivanek, O. L.; Murfitt, M. J.; Szilagyi, Z. S.; Lupini, A. R.; Borisevich, A.; Sides Jr., W. H.; Pennycook, S. Science 2004, 305, 1741.

82. Downing, K. H.; Glaeser, R. M. Ultramicroscopy 1986, 20, 269-278.

83. Bullough, P.; Henderson, R. Ultramicroscopy 1987, 21, 223-230.

84. Bang, J.; Lodge, T. P.; Wang, X.; Brinker, K. L.; Burghardt, W. R. Phys Rev Lett 2002, 89, 215505 1-215505 4.

85. Typke, D.; Downing, K. H.; Glaser, R. M. Microscopy and Microanalysis 2004, 10, 21-27.

86. Henderson, R.; Glaeser, R. M. Ultramicroscopy 1985, 16, 139-150.

87. Blacher, S.; Maquet, V.; Schils, F.; Martin, D.; Schoenen, J.; Moonen, G.; Jerome, R.; Pirard, J. P. Biomaterials 2003, 24, 1033-1040.
88. Sali, A.; Glaeser, R.; Earnest, T.; Baumeister, W. Nature 2003, 422, 216-225.

89. Spontak, R. J.; Fung, J. C.; Braunfeld, M. B.; Sedat, J. W.; Agard, D. A.; Kane, L.; Smith, S. D.; Satkowski, M. M.; Ashraf, A.; Hajduk, D. A.; Gruner, S. M. Macromolecules 1996, 29, 4494-4507.

90. Laurer, J. H.; Khan, S. A.; Spontak, R. J.; Satkowski, M. M.; Grothaus, J. T.; Smith, S. D.; Lin, J. S. Langmuir 1999, 15, 7947-7955.

91. (a) Kübel, C.; Voigt, A.; Schoenmakers, R.; Otten, M.; Su, D.; Lee, T.-C.; Carlsson, A.; Bradley, J. Microscopy and Microanalysis 2005, in press. (b) Midgely, P. A.; Weyland, M. Ultramicroscopy 2003, 96, 413-431.

92. Che, S.; Liu, Z.; Ohsuna, T.; Sakamoto, K.; Terasaki, O.; Tatsumi, T. Nature 2004, 429, 281-284.

93. Potter, C. S.; Chu, H.; Frey, B.; Green, C.; Kisseberth, N.; Madden, T. J.; Miller, K. L.; Nahrstedt, K.; Pulokas, J.; Reilein, A.; Tcheng, D.; Weber, D.; Carragher, B. Ultramicroscopy 1999, 77, 153-161.

94. Carragher, B.; Kisseberth, N.; Kriegman, D.; Milligan, R. A.; Porter, C. S.; Pulokas, J.; Reilein, A. J Struct Biol 2000, 132, 33-45.

95. Kirkmeyer, B. P.; Taubert, A.; Winey, K. Macromolecules 2002, 35, 2648-2653.

96. Taubert, A.; Wind, J. D.; Winey, K. Polymer 2002, 44, 1881-1892.

97. Taubert, A.; Winey, K. Macromolecules 2002, 35, 7419-7426.

98. Winey, K. I.; Laurer, J. H. Macromolecules 2000 , 33, 507-513.

99. Laurer, J. H.; Mulling, J. F.; Khan, S. A.; Spontak, R. J.; Bukovnik, R. J Polym Sci Part B: Polym Phys 1998, 36, 2379-2391.

100. Laurer, J. H.; Mulling, J. F.; Khan, S. A.; Spontak, R. J.; Lin, J. S.; Bukovnik, R. J Polym Sci Part B: Polym Phys 1998, 36, 2513-2523.

101. Treacy, M. M.; Gibson, J. M. Acta Crystallogr 1996, A52, 212-220.

102. Gibson, J. M.; Treacy, M. M. J.; Voyles, P. M. Ultramicroscopy 2000, 83, 169-178.

103. Voyles, P. M. Fluctuation electron microscopy of medium-range order in amorphous silicon, Doctoral dissertation, The University of Illinois, 2001.

104. Voyles, P. M.; Muller, D. A. Ultramicroscopy 2002, 93, 147-159.

105. Chen, X.; Sullivan, J. P.; Friedmann, T. A.; Gibson, J. M. Appl Phys Lett 2004, 84, 2823-2825.

106. Wang, Y. C.; Chou, T. M.; Libera, M.; Voelkl, E.; Frost, B. G. Microscopy and Microanalysis 1998, 4, 146-157.

107. Sakai, Y.; Kato, M.; Masuda, S.; Harada, Y. Surf Review and Lett 1998, 5, 1199-1211.

108. Rose, H. Optik 1987, 77, 26-34.

109. Rose, H. Optik 1990, 84, 91-107.

110. Martin, D. C. Macromolecules 1992, 25, 51715177. 
111. Hostetter, G. Master's Thesis, The University of Michigan, 2002.

112. Martin, D. C.; Thomas, E. L. Macromolecules 1991, 24, 2450-2460.

113. Drummy, L. F.; Voigt-Martin, I.; Martin, D. C. Macromolecules 2001, 34, 7416-7426.

114. Gonzalez-Ronda, L. Ph.D. Dissertation, The University of Michigan, 2000.

115. Schnurr, B.; MacKintosh, F. C.; Williams, D. R. M. Europhys Lett 2000, 51, 279-285.

116. Sinclair, D. J Appl Phys 1950, 21, 380-386.

117. Martin, D. C. Prog Organic Coatings 2003, 48, 332-336.

118. Miska, P. K.; Drummy, L. F.; Martin, D. C. Mater Res Soc Symp Proc 2003, 734, A5.4.1-A5.4.6.

119. Kübel, C.; Gonzalez-Ronda, L.; Drummy, L. F.; Martin, D. C. J Phys Org Chem 2000, 13, 816-829.

120. Drummy, L. F.; Kuebel, C.; Martin, D. C. Philos Mag 2004, 84 1955-1968.

121. CRC Handbook of Chemistry and Physics, 60th Edition. Weast, R. C., Ed. CRC Press, Inc.: Boca Raton, FL, 1979.

122. Kazumori, H. JEOL News 2002, 37E, 1.

123. Mourou, G.; Williamson, S. Appl Phys Lett 1982, $41,44-45$.

124. Williamson, S.; Mourou, G.; Li, J. C. M. Phys Rev Lett 1984, 52, 2364-2367.

125. Siwick, B. J.; Dwyer, J. R.; Jordan, R. E.; Miller, R. J. D. Science 2003, 302, 1382-1385.

126. Siwick, B. J.; Dwyer, J. R.; Jordan, R. E.; Miller, D. J. D. Chem Phys 2004, 299, 285-305.

127. Elsayed-Ali, H. E.; Mourou, G. A. Appl Phys Lett 1988, 52, 103-104.

128. Aeschlimann, M.; Hull, E.; Cao, J.; Schmuttenmaer, C. A.; Jahn, L. G.; Gao, Y.; Elsayed-Ali, H. E.; Mantell, D. A.; Scheinfein, M. R. Rev Sci Instrum 1995, 66, 1000-1009.

129. Zeng, X.; Elsayed-Ali, H. E. Surf Sci 2002, 2002, 373-384.

130. Ruan, C.-Y.; Vigliotti, F.; Lobastov, V. A.; Chen, S.; Zewail, A. H. Proc Natl Acad Sci USA 2004, 101, 1123-1128.

131. Ruan, C.-Y.; Lobastov, V. A.; Vigliotti, F.; Chen, S.; Zewail, A. H. Science 2004, 304, 80-84.

132. Srinivasan, R.; Lobastov, V. A.; Ruan, C.-Y.; Zewail, A. H. Helv Chim Acta 2003, 86, 1763-1838.

133. Ihee, H.; Lobastov, V. A.; Gomez, U. M.; Goodson, B. M.; Srinivasan, R.; Ruan, C.-Y.; Zewail, A. H. Science 2001, 291, 458-462.

134. Williamson, J. C.; Cao, J.; Ihee, H.; Frey, H.; Zewail, A. H. Nature 1997, 386, 159-162.

135. Schäfer, B.; Bostanjoglo, O. Optik 1992, 92, 913.

136. Heinrict, F.; Bostanjoglo, O. Appl Surf Sci 1992, 54, 244-254.
137. Bostanjoglo. O.; Marine. W.; Thomsen-Schmidt. P.Appl Surf Sci 1992, 54, 302-307.

138. Bostanjoglo, O.; Penschke, V.J Appl Phys 1993, 73, 8201.

139. Bostanjoglo, O.; Otte, D. Mater Sci Eng 1993, A173, 407-411.

140. Schäfer, B.; Knecht, T.; Bostanjoglo, O. J Appl Phys 1994, 75, 8027.

141. Bostanjoglo, O.; Niedrig, R.; Wedel, B. J Appl Phys 1994, 76, 3045-3048.

142. Balandin, V. Y.; Otte, D.; Bostanjoglo, O. J Appl Phys 1995, 78 2037-2044.

143. Balandin, V. Y.; Niedrig, R.; Bostanjoglo, O. J Appl Phys 1995, 77, 135.

144. Bostanjoglo, O.; Otte, D. Phys Status Solidi A 1995, 150, 163.

145. Bostanjoglo, O.; Nink, T. J Appl Phys 1996, 79, 8725-8729.

146. Otte, D.; Kieinschmidt, H.; Bostanjoglo, O. Rev Sci Instrum 1997, 68, 2534.

147. Balandin, V. Y.; Gernert, U.; Nink, T.; Bostanjoglo, O. J Appl Phys 1997, 81, 2835.

148. Bostanjoglo, O.; Weingärtner, M. Rev Sci Instrum 1997, 68, 2456-2460.

149. Bostanjoglo, O.; Nink, T. Appl Surf Sci 1997, 109/110, 101-105.

150. Niedrig, R.; Bostanjoglo, O. J Appl Phys 1997, 81, 480-485.

151. Weingärtner, M.; Bostanjoglo, O. Surf Coat Technol 1998, 100-101, 85-89.

152. Balandin, V. Y.; Nink, T.; Bostanjoglo, O. J Appl Phys 1998, 84, 6355.

153. Weingärtner, M.; Elschner, R.; Bostanjoglo, O. Appl Surf Sci 1999, 138-139, 499-502.

154. Nink, T.; Galbert, F.; Mao, Z. L.; Bostanjoglo, O. Appl Surf Sci 1999, 138-139, 439.

155. Domer, H.; Bostanjoglo, O. Adv Eng Mater 2002, 4, 632-625.

156. Domer, H.; Bostanjoglo, O. J Appl Phys 2002, 91, 5462-5467.

157. Domer, H.; Bostanjoglo, O. J Appl Phys 2003, 94, 6280-6284.

158. Domer, H.; Bostanjoglo, O. Appl Surf Sci 2003, 208-209, 442-446.

159. Domer, H.; Bostanjoglo, O. Rev Sci Instrum 2003, 74, 4369-4372.

160. Lovinger, A. J. Macromolecules 1985, 18, 910918.

161. Liao, J; Martin, D. C. Science 1993, 260, 1489 1491.

162. Liao, J; Martin, D. C. Philos Mag A 1996, 74, 195-213.

163. Liao, J.; Martin, D. C. Philos Mag A 1999, 79, 1507-1507.

164. Grubb, D. T. J Mater Sci 1974, 9, 1715-1736. 